\title{
İşletmelerin Finansal Başarısızlığının AHP Temelli ELECTRE TRI ve FLOWSORT Yöntemleri ile Tahmin Edilmesi ${ }^{1}$
}

\author{
Kenan Oğuzhan Oruç² \\ Kerime Demirbaş ${ }^{3}$
}

\begin{abstract}
İşletmelerin Finansal Başarısızlığının AHP Temelli ELECTRE TRI ve FLOWSORT Yöntemleri ile Tahmin Edilmesi

Öz
\end{abstract}

İşletmenin yükümlülüklerini karşılayamaması olarak tanımlanan finansal başarısızlık, mallarının tasfiye edilmesiyle sonuçlanan iflasa kadar uzanabilmektedir. İşletmelerin finansal başarısızlığa uğramaları sadece kendi paydaşlarına değil, aynı zamanda ülke ekonomisine de ciddi maliyetler yüklemektedir. Bundan dolayı finansal başarısızlığın tahmin edilmesi finans alanında önemli araştırma konularından birisidir. Bu çalışmada, ELECTRE TRI ve FLOWSORT yöntemlerinin sınıflama gücü karşılaştırılarak finansal başarısızlık tahmini yapılmıştır. Makalede; Borsa İstanbul'da işlem gören 30 gıda, içki ve tütün işletmesinin, uzman görüşleriyle belirlenen 10 finansal oranı kriter olarak belirlenmiştir. Finansal oranların önem ağırlıklarının hesaplanmasında ise Analitik Hiyerarşi Prosesi yöntemi kullanılmıştır. Elde edilen sonuçlara göre ELECTRE TRI yönteminin işletmeleri doğru sınıflandırma oranı \%77, FLOWSORT yöntemininse \%57 olarak gerçekleşmiştir.

Anahtar Kelimeler: ELECTRE TRI, FLOWSORT, Analitik Hiyerarşi Prosesi, Çok Kriterli Karar Verme, Finansal Başarısızlık

\section{Giriş}

Insanoğluna yaşamı boyunca karşılaştığı problemlere çözüm bulma düşüncesi sürekli hâkim olmuştur. Bireylerin olduğu kadar yöneticilerin dünyası da şimdiki ile gelecek zaman arasında değişim içindedir. Değişim ortamı içinde bireyler ve yöneticiler belirlemiş oldukları hedeflere ulaşmada sayısız karar verme problemiyle karşı karşıyadır. Bu bağlamda Çok Kriterli Karar Verme (ÇKKV) yöntemleri karar süreçlerinde karar vericilere (KV) yardımcı olmak amacıyla geliştirilmiş yöntemlerdir.

1 Bu çalışma Süleyman Demirel Üniversitesi Sosyal Bilimler Enstitüsü Ekonometri Anabilim Dalı’nda Doç. Dr. Kenan Oğuzhan ORUÇ danışmanlığında Kerime DEMIRBAŞ tarafından “iş̧letmelerin Finansal Başarısızlığının AHP Temelli ELECTRE TRI ve FLOWSORT Yöntemleri ile Tahmin Edilmesi” ismiyle tamamlanarak 18.06.2019 tarihinde savunulan yüksek lisans tezinden türetilmiştir.

2 Doç. Dr., Süleyman Demirel Üniversitesi IiBF, Ekonometri Bölümü, kenanoruc@sdu.edu.tr, Yazar ORCID Bilgisi: https://orcid.org/0000-0002-2276-8956

3 Süleyman Demirel Üniversitesi, Sosyal Bilimler Enstitüsü, Ekonometri ABD, Yüksek Lisans mezunu, kerime.demirbas@gmail.com, Yazar ORCID Bilgisi: https://orcid.org/0000-0002-5520-4727 
Karar verme problemleri; niteliklerine, KV'nin politikasına ve kararın genel amacına göre alternatif bir çözümün seçilmesi, alternatiflerin en iyiden en kötüye doğru sıralanması veya alternatiflerin önceden tanımlanmış sınıflara atanması şeklindedir. ÇKKV yöntemleri genellikle seçim ve sıralama problemlerinde sıkça kullanıımasına rağmen, 1980 'lerden sonra sınıflandırma problemlerinde de önemli araştırmalar yapılmıştır. Sınıflandırma problemleri mümkün olan daha yüksek sınıflandırma doğruluğunu ve tahmin yeteneğini gerçekleştirecek matematiksel modeller geliştirmek amacıyla, araştırmacıları bu tür problemleri çözmeye teşvik etmektedir. ÇKKV yöntemleri, sınıflandırma problemlerinden olan finansal başarısızlığın incelenmesi için de önemli bir araçtır.

İşletmelerin istenilen kârı elde edememesi, borcunu ödeyememesi, iflas etmesi vb. geniş bir yelpazede ele alınabilen finansal başarısızlık, çeşitli grupları ilgilendiren ve yüksek maliyet içeren bir kavramdır. Bundan dolayı finansal başarısızlığın tahmin edilmesi, gerek gelecekte başarısız olacak işletmelerde koruyucu ve düzeltici önlemler alabilmek, gerekse kötü performans sergileyen işletmeleri belirlemek açısından son derece önemlidir (Brabazon vd., 2002: 1011; Torun, 2007: 15). Finansal başarısızlığı tahmin edebilen modellerin geliştirilmesi ve kullanılması işletmeler için iki farklı şekilde önem arz etmektedir. İlk olarak, başarısızlığı önlemek mecburiyetinde olanlar (yani yöneticiler, yetkililer vb.) için çok yararlı olabilir. Bu faaliyetler sıkıntılı işletmenin birleşmesi, tasfiyesi, reorganizasyonu ve ilgili maliyetler hakkındaki kararları içerir. İkinci olarak bu tür modeller, birlikte çalışacakları veya yatırım yapacakları işletmelerin değerlendirilmesinde ve seçilmesinde, fırsat maliyeti ile başarısızlık riskini hesaba katarak finansal kurumların KV'lerine karar vermesinde yardımcı olabilir (Dimitras vd., 1996: 488; Ahn vd., 2000: 65). Ayrıca finansal başarısızlığın tahmin edilmesi yöneticiye, işletmenin durumu hakkında tarafsız ve gerçek bilgi sağlamaktadır. Buna ek olarak başarısızlığın erken tespiti, yöneticilere iş ilişkisinde bulunduğu işletmeler hakkında daha doğru kararlar vermesi açısından da önemli katkı sağlayacaktır. İşletme yöneticileri bu tip değerlendirmeleri kredili mal sattığı işletmelere de uygulayarak kredili satış politikasını belirleyebilir ve buradaki riski düşürebilir (Yıldız, 1999: 24).

Bu çalışmanın amacı, ÇKKV yöntemlerinin finansal olarak başarılı/başarısız işletmeleri belirlemedeki tahmin gücünü ölçmektir. Makalede, ÇKKV yöntemlerinden ELECTRE TRI ve FLOWSORT yöntemlerinin sınıflama gücü karşılaştırılarak finansal başarısızlık tahmini yapılmıştır. Çalışmada Borsa İstanbul'da (BiST) işlem gören 30 gıda, içki ve tütün işletmesi, uzman görüşüyle belirlenen 10 finansal oran kriteri ile finansal anlamda başarılı ve başarısız olarak sınıflandırılmıştır. Kriterlerin önem ağırlıklarının belirlenmesinde ise Analitik Hiyerarşi Prosesi (AHP) yöntemi kullanılmıştır.

Birçok ÇKKV yönteminde olduğu gibi ELECTRE TRI ve FLOWSORT yöntemlerinin uygulanabilmesi için kriterlerin yönünün maksimizasyon ya da minimizasyon şeklinde önceden belirlenmesi gerekmektedir. Ancak finansal oranlardan cari oran, kaldıraç oranı, kısa vadeli yabancı kaynaklar (KVYK) gibi oranların bir yönü bulunmamaktadır. Bu çalışmada, daha önceki çalışmalarda rastlanmayan bir yaklaşımla, kullanılan kriterlere yeni fonksiyonlar tanımlanarak ilk kez belirli bir yön verilmiştir. Ayrıca yapılan literatür incelemesi sonucunda, FLOWSORT yöntemi ile daha önce finansal başarısızık tahmininde yapılmış herhangi bir çalışmaya ulaşılamamıştır.

Makale altı bölüm olarak hazırlanmıştır. Çalışmanın ikinci bölümünde literatür özetine yer verilmiştir. Üçüncü bölümde; finansal başarısızlığın tanımı ve finansal performans ölçütlerine değinilmiş, yöntem dördüncü bölümde anlatılmıştır. Makalenin uygulaması beşinci bölümde yapılmış olup, son bölümde de sonuç ve önerilere yer verilmiştir. 


\section{Literatür Özeti}

Literatürde finansal başarısızlığın tahmin edilmesi üzerine pek çok çalışma yapılmıştır. Bu alanda yapılan ilk çalışmalarda genellikle tek değişkenli ve çok değişkenli istatiksel teknikler kullanılmıştır. Tek değişkenli istatiksel teknikler, daha yüksek tahmin doğruluğunu sağlayan önemli finansal oranları belirlemek amacıyla kullanılmıştır. Tek değişkenli istatistiksel teknikler kullanılarak yapına çalışmalar içinde kendisinden en çok söz edilen çalışma Beaver'in (1966) çalışmasıdır. Bu çalışmada, finansal başarısızlığı tahmin etmede finansal oranların gücü ölçülmüş ve bu oranların finansal başarısızlığı tahmin etmede kullanılabileceği sonucuna ulaşılmıştır.

Daha sonra diskriminant analizinin yanı sıra, logit ve probit analizleri de dâhil olmak üzere çok değişkenli istatiksel ve ekonometrik teknikler finansal başarısızlık alanında kullanılmaya başlanmıştır.

Altman (1968) ilk defa çoklu diskriminant analizini kullanarak finansal başarısızlığı tahmin etmede Z Skor modelini geliştirmiştir. Bu çalışmada, 1946-65 yılları arasında iflas eden 33 başarısız üretim işletmesi ile yine aynı sektördeki 33 başarılı işletme, literatürde daha önce kullanılan 22 finansal oran içinden en iyi 5 oran belirlenerek analiz edilmiştir. Kullanılan analiz başarısızlıktan bir yıl öncesini, \% 95 oranında doğru sınıflandırmıştır.

Ohlson (1980), finansal başarısızlığının tahmin edilmesinde logit modelini kullanmıştır. 1970-76 yılları arasından seçilen 105 başarısı işletme ile 2.058 başarılı işletmede yapılan gözlemlere dayanan çalışmada, iflastan 3 yı öncesi için 3 ayrı model geliştirilmiş ve doğru tahmin etme olasılıkları \% 90'ın üstünde olmuştur (Yıldız, 1999: 40).

Ünal'ın 1988 yılındaki yapmış olduğu çalışmadaki amacı, finansal başarısızlığı tahmin etmede kullanılabilecek temel finansal oranları belirlemek ve uygunluklarını analiz etmektir. Türkiye Gıda Sektörüne ait, 1979-84 yılları kapsayan, 33'ü başarısız, 62 işletmenin kullanıldığı çaIışma sonunda 50 finansal oran arasından 6 oran anlamlı bulunmuştur. Diskriminant analizi ile gerçekleştirilen çalışmada, \% 97 oranında doğru sınıflandırma elde edilmiştir (Altman ve Narayanan, 1997: 52-53).

Literatür incelendiğinde tek ve çok değişkenli istatiksel tekniklerin yanında bilgi ve bilgisayar bilimine dayanan kaba kümeler, uzman sistemler, yapay sinir ağları, çok kriterli karar destek sistemleri ve bu makalede de ele alınan ÇKKV yöntemleri son zamanlarda finansal başarısızlık tahmininde sıkça kullanılmıştır.

Slowinski ve Zopounidis (1995), finansal başarısızlık riskinin analizi ve değerlendirilmesi için kaba kümeler yaklaşımını kullanmışlardır. Bu çalışmada; 1988 yılı için 39 işletmeden; 20'si başarılı, 9'u başarısız ve 10'u belirsiz olmak üzere 3 risk kategorisine ayrılmıştır. İşletmeler 6'sı nicel (finansal oranlar) ve diğer altısı niteliksel olacak şekilde toplamda 12 kritere göre değerlendirilmiştir. Çalışma sonunda nicel kriterlerin finansal başarısızlık tahmininde daha önemli kriterler olduğu sonucuna ulaşılmıştır.

Doumpos ve Zopounidis (2002), gelişen ÇKKV sınıflandırma modellerinin finans ve bankacılık alanlarındaki etkinliğini araştırmışlardır. Bu doğrultuda üç ÇKKV sınıflandırma yöntemi göz önünde bulundurulmuştur. Bunlar; UTADIS yöntemi, ELECTRE TRI yöntemi ve kaba set yaklaşımıdır. Makalede, bu yöntemlerin finansal başarısızlık tahmini, kredi riski değerlendirmesi ve stok ölçüm problemleri üzerindeki performansları araştırılmıştır. Çalışma sonunda, ÇKKV yaklaşımına ait sınıflandırma modellerinin finans ve bankacılık alanlarında, geleneksel istatistiksel tekniklerle karşılaştırılabilir ve alternatif olarak değerlendirilebileceği sonucuna ulaşılmıştır. 
Vatansever ve Aydın (2014), Türkiye'de 2012 yılında BiST'te işlem gören Gıda, İçki ve Tütün sektörüne ait 8 işletmeye yönelik finansal başarı ve başarısızlık tahminini yapmışlardır. Çalışmada geliştirilen modelde değişken olarak finansal oranlar kullanılmıştır. Öncelikle 43 finansal orana ayırma analizi uygulanmış ve \% 5 anlamlılık düzeyinde 5 finansal oran işletmeleri ayırmada anlamlı bulunmuştur. Sonrasında elde edilen finansal oranlar ELECTRE TRI modelinde kriter olarak kullanılmıştır. İşletmeleri sınıflandırmada ELECTRE TRI modelinin başarılı bir yöntem olduğu vurgulanmıştır.

Literatürde bu çalışmada kullanılan FLOWSORT yöntemi ile finansal başarısızlık tahmini üzerine yapılmış bir çalışmaya ulaşılamamıştır. Söz konusu yöntemle ilgili diğer alanlarda yapılan çalışmalardan bazıları ise aşağıda özetlenmiştir.

Nemery ve Lamboray (2008), PROMETHEE metodolojisine dayanarak, merkezi veya sınır kesitleri tarafından tanımlanan sıralı sınıflara alternatiflerin atanmasını sağlayan FLOWSORT yöntemini ilk olarak önermişlerdir.

Genç (2013); ELECTRE TRI ve FLOWSORT yöntemlerini bir arada kullanarak, G7 ülkelerinin makroekonomik kriterlere göre sınıflandırmasını yapmıştır. Her iki yöntemin de tutarlı olduğu ve benzer sonuçlar ortaya koyduğu tespit edilmiştir.

Sepulveda ve Derpich (2014), lojistik hizmet sağlayıcısının tedarikçi değerlendirme sürecini ele almışlardır. Çalışmada kullanılan FLOWSORT yönteminde; iyi tedarikçi, gelecek vaat eden tedarikçi ve değiştirilecek tedarikçi olmak üzere üç kategori tanımlanmıştır. Değerlendirmede kriter olarak ekonomi, hizmet ve kalite kullanılmıştır. Çalışma sonucunda FLOWSORT yönteminin, tedarikçi değerlendirme probleminin çözümünde etkili bir araç olduğu vurgulanmıştır.

Campos vd (2015), bulanık küme teorisi ile FIOWSORT yöntemini bir arada kullanarak eldeki verilerin belirsizlik içerdiği durumlar için kullanılabilecek Bulanık FLOWSORT yöntemini önermişlerdir. Yöntemin uygulanabilirliğini kurgusal bir problem ile test etmişlerdir.

Es vd. (2016), FLOWSORT ve K-ortalamalar kümele yöntemlerini karşılaştırmalı kullanarak, G-20 ülkelerini Ar-Ge ve yenilikçilik kriterlerine göre güçlü, orta ve zayıf olmak üzere sınıflandırmışlardır. Çalışma sonucunda; kullanılan yöntemlerin yapı itibari ile birbirinden farklı olsa da, benzer sonuçlar üretebileceği sonucuna ulaşılmıştır.

Sarrazin vd (2017), FLOWSORT ve PROMETHEE yöntemlerinin temel prensiplerini kullanarak PCLUST ismini verdikleri bir model önermişlerdir. Önerilen model sınıflandırma problemlerinin çözümü için kullanılabilmektedir.

\section{Finansal Başarısızlık}

Ticari işletmeler cari piyasa değerini maksimize etmek ve faaliyetlerinin devamlılığını sağlamayı hedefleyerek kurulur. Fakat işletmeler bu süreçte birbirinden farklı sıkıntılarla karşılaşabilir. Sıkıntıların nedeninin belirlenememesi ve çözüme ulaştırılamaması işletmeleri başarısızlığa sürüklemektedir (Gitman, 1992: 616). Literatürde finansal sıkıntıyı tanımlamak için çeşitli terimler kullanılmaktadır. En yaygın kullanılan terimler ise başarısızlık, pasifi aktifinden fazla borcunu ödeyemezlik, temerrüde düşme ve iflastır. Bu terimlerin hepsi ekonomik ve finansal problemleri işaret etmektedir. İsteğe bağı olarak birbirleri yerine kullanılsalar da, bu terimler inceleme altındaki işletmelerin kendine özgü veya koşullarıyla ilgili olarak farklı tanımlar sağlarlar (Zopounidis ve Paraschou, 1998: 1). Literatürde diğer terimlere karşın finansal başarısızlığın genel kabul görmüş tek bir tanımı bulunmamaktadır. Yapılan çalışmalardaki finansal başarısızlık 
tanımları, belirli bir risk düzeyinde yatırılan sermayeden beklenen getirinin elde edilememesinden, işletmenin mallarının tasfiye edilmesiyle sonuçlanan iflasa kadar uzanmaktadır (Torun, 2007: 5).

İ̧̧letmelerin performanslarını belirlemek, değerlendirmek ve geçmiş veriler ya da diğer işletmelerle karşılaştırabilmek için kullandıkları tablolara finansal tablolar adı verilmektedir (Ercan ve Ban, 2005: 21). Finansal tablo verilerinden elde edilebilecek çok sayıda oran, taşıdıkları ortak özellikler ve oranları analiz edecek kişilerin ilgi alanlarına göre farklı gruplara ayrılabilirler. Hissedarlar daha ziyade işletmenin kârlılığı ile ilgilenirken, yöneticiler için faaliyet oranları, işletmeye kısa süreli borç verenler için likidite, uzun süre borç sağlayanlar için sermaye yeterliliği öncelik taşıyabilir. Genel olarak oranlar aşağıdaki gibi sınıflandırılmaktadır (Bolak, 1998: 29-30):

- Likidite oranları

- Finansal yapı oranları

- Kârlılık oranları

- Faaliyet oranları

Finansal başarısızlık tahmin modelleri geliştirilirken de çoğunlukla, temel finansal oranlardan yararlanılmaktadır (Aktaş, 1997: 20). Bu makalede; bu sınıflandırmanın altındaki 10 oran kriter olarak kullanılmıştır.

\section{Araştırmanın Yöntemi}

Karar bilimi, teorik ve pratik alanda çok geniş ve hızla gelişen bir araştırma alanıdır. Literatürde Bernard Roy (1981) tarafından, dört farklı karar verme problemi tanımlamıştır. Bu problemler; seçim, sınıflandırma, sıralama ve tanımlama problemleridir. Buradaki sınıflandırma problemindeki amaç; tanımlayıcı, örgütsel veya öngörüsel nedenlerle benzer davranış veya özellikler içeren seçenekleri yeniden gruplamaktır (Ishizaka ve Nemery, 2013: 3). Bu problemler, sınıflandırma modelleri oluşturmak için çok sayıda teknik geliştirilmesine sebep olmuştur. Geliştirilen tekniklerden birisi de ÇKKV yöntemleridir.

ÇKKV; karar verme sürecinde birçok kriteri eş zamanlı olarak değerlendirerek, birden çok alternatifin sınıflandırılması, sıralanması, tanımlanması veya en iyi alternatifin seçilmesine olanak sağlayan bir karar verme aracıdır. ÇKKV yöntemlerinin işlem merkezine KV'yi yerleştirilmesi özelliğine sahiptir. Bu sebeple yöntemler, KV'ye uzlaşma çözümü bulmak için basamak ve teknik sağlarlar. Bu yöntemler, her KV için aynı çözüme götüren otomatikleştirilebilir yöntemler değildir ve öznel (subjektif) bilgi içerirler. Ayrıca bu öznel bilgiler KV tarafından sağlanmaktadır (Ishizaka ve Nemery, 2013: 1-3).

Literatürde önerilmiş pek çok ÇKKV yöntemi vardır. Bu çalışmada; kriter ağırlıklarının belirlenmesi sürecinde öznel bir ağırlıklandırma yöntemi olan AHP yöntemi, finansal başarılı/başarıSIz işletmelerin sınıflandırılma sürecinde ise ELECTRE TRI ve FLOWSORT yöntemleri kullanılmıştır.

Bu makalede ele alınan işletmelerin finansal başarısızlığının tahmin edilmesi problemi bir sınıflandırma problemidir. Sınıflandırma problemleri için literatürde AHPSORT, UTADIS, FLOWSORT, ELECTRE TRI gibi önerilmiş pek çok yöntem bulunmaktadır. Yapılan literatür incelemesinde FLOWSORT yöntemi ile daha önce finansal başarısızlık tahmininde herhangi bir çalışmaya ulaşılamamış olması bu yöntemin seçilmesinin ana sebebidir. FLOWSORT yönteminin sınıflandırma başarısındaki gücünü görmek amacıyla da sınıflandırma problemleri için literatürde daha çok tercih edilen ELECTRE TRI yöntemi alternatif yöntem olarak tercih edilmiştir. 


\subsection{ELECTRE TRI Yöntemi}

ELECTRE TRI, önceden tanımlanmış sınıflara alternatiflerin atanmasını sağlayan çok kriterli bir sınıflandırma yöntemidir. $m$ adet $k r i t e r\left(g_{j}\right)$ için $(j=\{1,2, \ldots, m\}), p+1$ adet sınıf $\left(C_{h}\right)$ tanımlanmış olsun ( $(h=\{1,2, \ldots, p\})$. Kesit (sınır değer- $\left.b_{h}\right), C_{h}$ sınıfının üst limiti ve $C_{h+1}$ sınıfının alt limitini ifade etmek üzere; kriterler, kesitler ve sınıflar arasındaki ilişkiler şekil 1'de gösterilmiştir $\left(b_{p+1}\right.$ ve $b_{0}$, ideal ve ideal olmayan kesit değerlerini ifade etmektedir). ELECTRE TRI yönteminde alternatif (a)'nın herhangi bir sınıfa atama işlemi, sınıfların sınırlarını tanımlayan kesitler ile alternatifin karşılaştırılması yoluyla gerçekleştirilmektedir (Mousseau vd., 2000: 759).

Şekil 1. Kesit (Sınır) Değerlerini Kullanarak Sınıfların Oluşturulması

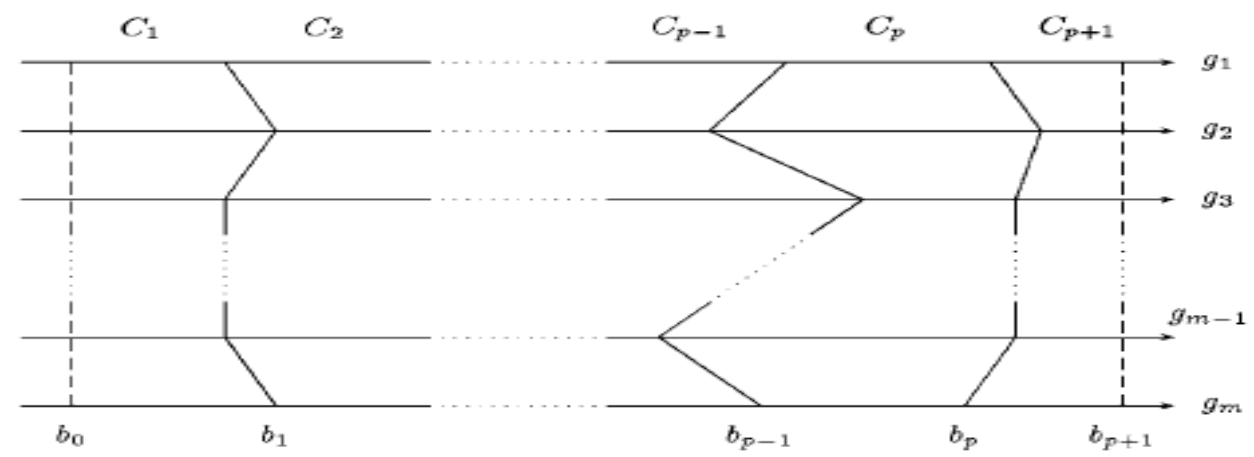

Kaynak: Mousseau vd., 2000: 760.

ELECTRE TRI yönteminin uygulanabilmesi için öncelikle aşağıda tanımlanmış olan parametrelerin belirlenmesi gerekmektedir. Bu parametrelerin kümesi, KV'nin bir tercih modeli oluşturması için kullanılmaktadır (Kılıç, 2005: 342):

- Sınıflar arasındaki sınır değerleri $\left(g_{j}\left(b_{h}\right)\right)$,

- Kriterlere verilen ağırlıklar $\left(w_{j}\right)$,

- $\quad$ Eşik değerleri $\left(\mathrm{q}_{\mathrm{j}}\left(\mathrm{b}_{\mathrm{h}}\right), \mathrm{p}_{\mathrm{j}}\left(\mathrm{b}_{\mathrm{h}}\right)\right)$.

ELECTRE TRI yönteminin uygulama adımları aşağıdaki gibidir (Kılıç, 2005: 342-344):

Adım 1. Her bir kriter için sınır değerleri aşağıdaki formül yardımıyla bulunur.

$$
g_{j}\left(b_{h}\right)=\frac{1}{2}\left\{\frac{\sum g_{j}(a)}{\eta_{h}}+\frac{\sum g_{j}(a)}{\eta_{h+1}}\right\}
$$

Burada $g_{j}(a)$, alternatif a'ya ait kriter gj'yi temsil etmektedir. $\eta_{h}$ ve $\eta_{h+1}, C_{h}$ ve $C_{h+1}$ sınıflarına atanan alternatiflerin sayısıdır.

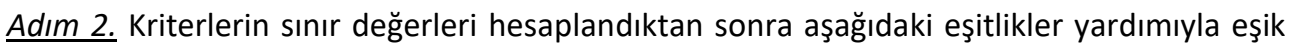
değerleri hesaplanır. Bu değerler rastgele olarak sabitlenmiştir (Mousseau ve Slowinski, 1998: 170).

$$
\begin{aligned}
& q_{j}\left(b_{h}\right)=0,05 g_{j}\left(b_{h}\right) \\
& p_{j}\left(b_{h}\right)=0,1 g_{j}\left(b_{h}\right)
\end{aligned}
$$

Adım 3. Her bir alternatif (a) için kriter $\left(\mathrm{g}_{\mathrm{j}}\right)$ değerlerine dayanarak marjinal başarı indeks değerleri $\left[\mathrm{C}_{\mathrm{j}}\left(a, \mathrm{~b}_{\mathrm{h}}\right)\right]$ ve marjinal başarısızlık indeks değerleri $\left[\mathrm{C}_{\mathrm{j}}\left(\mathrm{b}_{\mathrm{h}}, a\right)\right]$ hesaplanır. Marjinal başarı ve başarısızlık indeks değerleri 0 ile 1 arasında değer almaktadır. Bu indeksler kriterin yönüne göre farklı denklemler kullanılarak hesaplanmaktadır. 
Artan değere sahip kriterler için alternatiflerin marjinal başarı ve marjinal başarısızlık indeks değerleri sırasıyla (4) ve (5) fonksiyonları kullanılarak hesaplanır:

$$
\begin{aligned}
& C_{j}\left(a, b_{h}\right)=\left\{\begin{array}{l}
0, \text { e ğer } g_{j}(a) \leq g_{j}\left(b_{h}\right)-p_{j}\left(b_{h}\right) \text { ise } \\
1, \text { ĕ } e r g_{j}(a)>g_{j}\left(b_{h}\right)-q_{j}\left(b_{h}\right) \text { ise } \\
\frac{g_{j}\left(b_{h}\right)+p_{j}\left(b_{h}\right)-g_{j}(a)}{p_{j}\left(b_{h}\right)-q_{j}\left(b_{h}\right)}, \quad \text { d.d. }
\end{array}\right. \\
& \mathrm{C}_{\mathrm{j}}\left(\mathrm{b}_{\mathrm{h}}, a\right)=\left\{\begin{array}{l}
0, \text { e ğer } g_{j}(a) \geq g_{j}\left(b_{h}\right)+p_{j}\left(b_{h}\right) \text { ise } \\
1, \text { e } \mathrm{g} e r g_{j}(a)<g_{j}\left(b_{h}\right)+q_{j}\left(b_{h}\right) \text { ise } \\
\frac{g_{j}\left(b_{h}\right)+p_{j}\left(b_{h}\right)-g_{j}(a)}{p_{j}\left(b_{h}\right)-q_{j}\left(b_{h}\right)}, \quad \text { d.d }
\end{array}\right.
\end{aligned}
$$

Azalan değere sahip kriterler için ise alternatiflerin marjinal başarı ve marjinal başarısızlık indeks değerleri sırasıyla (6) ve (7) fonksiyonları kullanılarak hesaplanır:

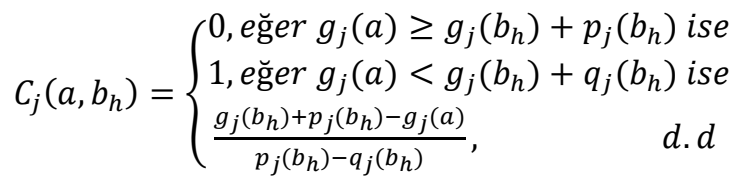

$$
\begin{aligned}
& \mathrm{C}_{\mathrm{j}}\left(\mathrm{b}_{\mathrm{h}}, a\right)=\left\{\begin{array}{l}
0, \text { ĕ } \mathrm{er} g_{i}(a) \leq g_{j}\left(b_{h}\right)-p_{j}\left(b_{h}\right) \text { ise } \\
1, \text { ĕger } g_{i}(a)>g_{j}\left(b_{h}\right)-q_{j}\left(b_{h}\right) \text { ise } \\
\frac{g_{j}\left(b_{h}\right)+p_{j}\left(b_{h}\right)-g_{j}(a)}{p_{j}\left(b_{h}\right)-q_{j}\left(b_{h}\right)}, \quad \text { d.d }
\end{array}\right.
\end{aligned}
$$

Adım 4. Marjinal başarı ve başarısızık indeks değerleri, kriter ağırlıkları $\left(w_{j}\right)$ ile çarpılarak; toplam başarı indeks değerleri (8) ve toplam başarısızlık indeks değerleri (9) elde edilir.

$$
\begin{aligned}
& \sum_{j=1}^{m} w_{j} C_{j}\left(a, b_{h}\right) \\
& \sum_{j=1}^{m} w_{j} \mathrm{C}_{\mathrm{j}}\left(\mathrm{b}_{\mathrm{h}}, a\right)
\end{aligned}
$$

Adım 5. Toplam başarı ve başarısızlık indeks değerleri skor kesme düzeyi olan Lamda $(\lambda=0,5)$ ile karşılaştırılır. Her alternatif için toplam başarı indeks değeri $\sum_{j=1}^{m} w_{j} C_{j}\left(a, b_{h}\right) \geq \lambda$ ve toplam başarısızlık indeks değeri $\sum_{j=1}^{m} w_{j} \mathrm{C}_{\mathrm{j}}\left(\mathrm{b}_{\mathrm{h}}, a\right) \leq \lambda$ ise, alternatif doğru sınıfa atanır. Aksi halde ilgili alternatifin atandığı sınıf yanlıştır.

\subsection{FLOWSORT Yöntemi}

FLOWSORT yöntemi ise PROMETHEE metodolojisi üzerine inşa edilmiş, ELECTRE TRI yöntemine benzer şekilde (şekil 1), merkezi veya sınırlandırıcı kesitler aracılığıyla önceden tanımlanan sınıflara alternatiflerin atanmasını sağlayan çok kriterli bir sınıflandırma yöntemidir (Es vd., 2017: 327). PROMETHEE yöntemi, KV'ye çok kriterli problemleri çözmek için alternatifler arasındaki ikili ilişkiyi kullanarak bir destek sunar. Bu ilişki PROMETHEE yönteminin tercih yapısını tanımlar (Sarrazin vd., 2017: 2). FLOWSORT yönteminin PROMETHEE yönteminden farkı ise, ikili ilişkinin sınırlandırıcı kesitler ile alternatifler arasında olmasıdır.

Yöntemin uygulama adımları şu şekildedir:

Adım 1. KV tarafından alternatifler $\left(\mathrm{a}_{\mathrm{i}}\right)$, kriterler $\left(\mathrm{g}_{\mathrm{j}}\right)$ ve kriter ağırlıklarını $\left(\mathrm{w}_{\mathrm{j}}\right)$ belirlenir.

Adım 2. Yine KV tarafından sınıfların sınır değerleri belirlenir $\left(r_{h}\right)$.

Adım 3. PROMETHEE metodolojisinde tanımlanmış olan tercih fonksiyonlarından $(\mathrm{P}(\mathrm{x}, \mathrm{y}))$ yararlanarak, sınır değerlerinin ve alternatiflerin tercih dereceleri $(\pi(x, y))$ hesaplanır. Tercih fonksiyonu belirli bir kriter baz alınarak değerlendirilen, $[0,1]$ aralığında değer alabilen $\mathrm{x}$ ve y gibi 
karar noktası arasındaki farkı ifade etmektedir. Brans ve Vincke (1985) tarafından KV'nin seçimini kolaylaştırmak için olağan, U, V, Seviyeli, Doğrusal ve Gaussian olmak üzere altı farklı tipte tercih fonksiyonu önerilmiştir (Dağ ve Yıldırım, 2015: 179).

FLOWSORT yönteminde tercih derecelerinin hesaplanma sürecinde, öncelikle alternatifler ile sınıfların kesit değerleri aracılığıyla bir küme oluşturulur. Sınıflara atanacak alternatif ai ile sınıfların kesitleri $\left(R^{*}=\left\{r_{1}{ }^{*}, r_{2}{ }^{*}, \ldots\right\}\right)$ ile oluşturulan küme $R_{i}{ }^{*}=R^{*} U\left\{a_{i}\right\}$ olacak şekilde birleştirilir (Genç, 2013: 335-336). KV'nin tercihine göre, y alternatifi üzerinde $x$ alternatifinin tercih kuvvetini değerlendiren bir tercih derecesi söz konusudur ve (10) ile (11) kullanarak hesaplanır (Brans ve Mareschal, 2005: 171).

$$
\begin{aligned}
& \pi(x, y)=\sum_{j=1}^{m} w_{j} P_{j}(x, y) \\
& \pi(y, x)=\sum_{j=1}^{m} w_{j} P_{j}(y, x)
\end{aligned}
$$

Adım 4. PROMETHEE yönteminin ikili tercih yapısından yararlanılarak pozitif, negatif ve net akımlar hesaplanır. Fakat PROMETHEE yönteminin aksine bu ikili ilişki, ELECTRE TRI yönteminde olduğu gibi sınırlandırıcı kesitler ile alternatifler arasındadır. Pozitif, negatif ve net akım değerleri aşağıdaki denklemler yardımıyla hesaplanmaktadır:

Pozitif akım:

$$
\phi_{R_{i}^{*}}^{+}(x)=\frac{1}{\left|R_{i}^{*}\right|-1} \sum_{r_{1}^{*} \in R_{i}^{*}} \pi\left(a_{i}, r_{1}^{*}\right)
$$

Negatif akım:

$$
\phi_{R_{i}^{*}}^{-}(x)=\frac{1}{\left|R_{i}^{*}\right|-1} \sum_{r_{1}^{*} \in R_{i}^{*}} \pi\left(r_{1}^{*}, a_{i}\right)
$$

Net akım:

$$
\phi_{R_{i}^{*}}(x)=\phi_{R_{i}^{*}}^{+}\left(a_{i}\right)-\phi_{R_{i}^{*}}^{-}\left(a_{i}\right)
$$

Pozitif akım, bir alternatifin diğer alternatiflere nasıl üstün geldiğinin bir göstergesidir. Başka bir ifadeyle, pozitif akım ne kadar yüksekse o alternatif diğerlerine göre daha iyi bir seçimdir. Negatif akım, bir alternatifin diğer alternatifler tarafından nasıl bastırıldığının bir göstergesidir. Ne kadar düşük olursa o alternatif diğerlerine göre daha iyi bir seçimdir (Brans ve Mareschal, 2005: 173).

Adım 5. Pozitif, negatif ve net akımlar hesaplandıktan sonra alternatifler aşağıda verilen sınıflandırma kuralları ile sınıflara atanır.

Sınıflandırma kuralı 1:

$$
C_{\phi^{+}}\left(a_{i}\right)=C_{h} \text {, eğer } \phi_{R_{i}}^{+}\left(r_{h}\right) \geq \phi_{R_{i}}^{+}\left(a_{i}\right)>\phi_{R_{i}}^{+}\left(r_{h+1}\right)
$$

Sınıflandırma kuralı 2:

$$
C_{\phi^{-}}\left(a_{i}\right)=C_{h} \text {, eğer } \phi^{-}{ }_{R_{i}}\left(r_{h}\right)<\phi_{R_{i}}^{-}\left(a_{i}\right) \leq \phi^{-}{ }_{R_{i}}\left(r_{h+1}\right)
$$

Sınıflandırma Kuralı 3:

$$
C_{\phi}\left(a_{i}\right)=C_{h} \text {, eğer } \phi_{R_{i}}\left(r_{h}\right) \geq \phi_{R_{i}}\left(a_{i}\right)>\phi_{R_{i}}\left(r_{h+1}\right)
$$

Atamanın olabilmesi için hem pozitif hem de negatif sınıflandırma kurallarının eş zamanlı sağlanması gerekmektedir. Eğer alternatifler pozitif ve negatif atama kurallarını eş zamanlı sağlamıyorsa, net akımlara göre sınıflara atanırlar (Nemery, 2009: 142). 


\subsection{Kriter Ağırlıklandırması: AHP Yöntemi}

Öznel ağırlıklandırma yöntemlerinden olan AHP, nicel ve nitel kriterleri ikili karşılaştırma yaparak ölçen, kriterlerin birbirlerine göre önem ağırlıklarını belirleyen ve öncelik sıralamasını esas alan bir yöntemdir (Akkaya vd., 2015: 9567; Can ve Arıkan, 2014: 647). Kriter ağırlıklarının hesaplanması sürecinde AHP'de aşağıdaki adımlar uygulanır (Saaty, 2008: 85; ):

Adım 1. Belirlenmiş kriterler arasında ikili karşılaştırmalar yapılır. İkili karşılaştırmalar için Tablo 1'deki ölçek kullanılmaktadır. İkili karşılaştırma ölçeği, her bir kriterin kendisiyle karşılaştırılan diğer kritere göre kaç kat tercih edildiğini gösterir.

Tablo 1. Ikili Karşılaştırma Ölçeği

\begin{tabular}{c|c}
\hline Dereceler & Tanımlama \\
\hline 1 & Eşit Düzeyde Önemli \\
3 & Orta Düzeyde Önem \\
5 & Güçlü Düzeyde Önem \\
7 & Çok Güçlü Düzeyde Önem \\
9 & Mutlak Düzeyde Önem \\
$2,4,6,8$ & Ara (Ortalama) Değerler \\
\hline
\end{tabular}

Kaynak: Saaty, 2008: 86.

$X_{i j}$; i. kriterin, j. kritere göre önem derecesi olmak üzere, $m$ adet kriter için Tablo 2'deki gibi ikili karşılaştırmalarda oluşan bir matris oluşturulur.

Tablo 2. n ikili Karşılaştırma Ölçeği

\begin{tabular}{l|cccc}
\hline & Kriter 1 & Kriter 2 & $\ldots$ & Kriter m \\
\hline Kriter 1 & 1 & $X_{12}$ & $\ldots$ & $X_{1 m}$ \\
Kriter 2 & $1 / X_{12}$ & 1 & $\ldots$ & $X_{2 m}$ \\
$\ldots$ & & & 1 & 1 \\
Kriter m & $1 / X_{1 m}$ & $1 / X_{2 m}$ & $\ldots$ & 1 \\
\hline
\end{tabular}

Kaynak: Vargas, 1990: 4.

Adım 2. ikili karşılaştırma matrislerinin oluşturulmasından sonra, normalleştirilmiş matris oluşturulur. Normalleştirilmiş matris, her bir sütun değerinin ayrı ayrı ilgili sütun toplamına bölünmesi ile elde edilmektedir (Dağdeviren ve Eren, 2001: 43).

Adım 3. Son olarak normalize edilmiş matristeki satır elemanlarının ortalaması alınarak her bir alternatif için kriter ağırlıkları belirlenir.

Adım 4. Yapılan ikili karşılaştırmalar öznel temellere dayandığı için yanılmalar ve tutarsızlıklar ortaya çıkabilmektedir. Bu durumu ölçmek için AHP yönteminde tutarlılık oranı (TO) kullanılmaktadır. Bu oranın 0,1'den küçük olması karşılaştırma matrisinin tutarlı olduğunu göstermektedir (Önder ve Önder, 2015: 32). TO’nın hesaplanması sürecinde öncelikle Tutarlılık Göstergesinin (TG) hesaplanması gereklidir. TG değeri (18) kullanılarak hesaplanır.

$$
T G=\left(\lambda_{\text {maks }}-n\right) /(n-1)
$$

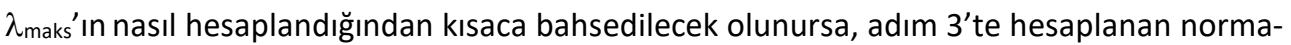
lize edilmiş satır elemanlarının ortalaması alınır ki bu öncelikler vektörünün hesaplanması demektir. Öncelikler vektörü hesaplandıktan sonra elde edilen vektör, en başta oluşturulan karşılaştırma matrisi ile çarpılarak tüm öncelikler matrisi oluşturulur. Tüm öncelikler matrisi, öncelikler vektörü elemanlarına bölünür ve tüm değerlerin ortalaması alınır. Bu ortalama $\lambda_{\text {maks'tır. }}$ 
Tutarlılık Oranı ise, TG değerinin Tablo 3'te karşılık gelen rastgele değer indeks (RI) değerine bölünmesiyle elde edilir (Triantaphyllou ve Mann, 1995: 4-5).

$$
T O=T G / R I
$$

Tablo 3. Rastgele Değer indeksi

\begin{tabular}{|c|c|c|c|c|c|c|c|c|c|c|c|c|c|c|c|}
\hline $\mathbf{N}$ & 1 & 2 & 3 & 4 & 5 & 6 & 7 & 8 & 9 & 10 & 11 & 12 & 13 & 14 & 15 \\
\hline RI & 0 & 0 & 0,5 & 0,9 & 1,1 & 1,3 & 1,4 & 1 & 1,5 & 1,5 & 1,5 & 1,5 & 1,6 & 1,6 & 1,6 \\
\hline
\end{tabular}

Kaynak: Saaty, 2007: 129.

\section{Uygulama}

\subsection{Alternatifler, Öngörü Seti ve Kriterlerin Belirlenmesi}

Çalışmada kullanılan alternatifler; 2010-2017 yılları arasında BiST'te işlem gören gıda, içki ve tütün sektörüne ait 30 işletmeden oluşmaktadır.

Makalenin öngörü setinin oluşturulmasında ise; başarısız işletmeler için 3. bölümün ilk paragrafındaki tanımdan hareketle finans literatüründe başarısız işletmelerin belirlenmesinde kullanılan (Aktaş 1997: 98; Keskin 2002: 85; Doğrul 2009: 109; Kurtaran Çelik 2009: 111) ve aşağıda belirtilen başarısızık kriterlerinden bir ya da birden fazlasını sağlaması kriteri dikkate alınmıştır:

- Iflas etmesi

- En az üst üste 3 yıl zarar etmiş olması

- BIST Yönetim Kurulu'nca hisse senetleri borsa kotundan çıkarılması

Bu kriterler doğrultusunda, 2010-2017 yılları arasında BiST'te işlem gören işletmelerinin 8 mali yılını kapsayan bilanço ve gelir tabloları incelenmiş ve inceleme sonunda üç yıl üst üste zarar eden işletmeler finansal anlamda başarısız olarak kabul edilmiştir. Daha sonrasında iflas eden ve borsa kotundan çıkarılan işletmeler ise KAP'ta bildirim sorgudan, düzenleyici kurum bildirimleri menüsünden taranarak tespit edilmiştir. Seçilen işletmelerin iflas ettikleri ve kottan çıkarıldıkları yıllar başarısızlık başlangıç yılı olarak kabul edilirken, "üç yıl üst üste zarar" etme kriterine uyan işletmelerin, ancak üçüncü yılda kritere tam uygunluk göstermeleri nedeniyle zarar ettikleri üçüncü yıl başarısızlık başlangıç yılı olarak kabul edilmiştir. Çoklu yıl çalışılmasının sebebi ise, belli bir yıl itibari ile çalışma için yeterli sayıda başarısız işletme bulmadaki sıkıntıdan kaynaklanmaktadır. Fakat farklı yıla ait finansal tabloların sanki aynı yıla aitmiş gibi bir arada kullanılması beraberinde enflasyon etkisini de ortaya çıkarmaktadır. Karşılaşılan bu sorun yalın muhasebe rakamları yerine finansal oranların kullanılmasıyla ortadan kalkabilmektedir (Aktaş, 1997: 99).

Finansal açıdan başarılı işletmeler ise yukarıda bahsedilen kriterlerden hiç birine uymayan işletmelerdir. Ama buradaki önemli bir konu ise başarılı işletmelerin finansal tablo verilerinde hangi yıla ait verilerin kullanılacağı sorusuna cevap vermektir. Bu noktada izlenen yaklaşım, en fazla karşılaşılan başarısızlık yııını finansal başarı başlangıç yılı olarak almak şeklinde olmuştur. Bu çalışmada en fazla başarısızlık yılı 2015 yılına aittir. Bu yüzden bu yıl finansal açıdan başarılı işletmelerin başarı başlangıç yılı olarak kabul edilmiştir.

Makalede, yukarıda açıklanan kapsam ve kriterler doğrultusunda 15'i başarısız, 15'i başarılı, toplamda 30 işletmeden oluşan bir öngörü seti elde edilmiştir. Elde edilen öngörü seti, uygulanan ELECTRE TRI ve FLOWSORT yöntemlerin tahmin başarısını ölçmek için kullanılmıştır. Çalışmada kullanılan işletmelerin listesi, başarılı-başarısız olma durumları ve başarı-başarısızlık başlangıç yılları Tablo 4'te verilmiştir. 
Tablo 4. Çalışmanın Öngörü Setini Oluşturan Iş̧letmeler

\begin{tabular}{|c|c|c|c|}
\hline Kod & İşletme Unvanı & Durum & $\begin{array}{c}\text { Başarı/Başarısızlık Başlangıç } \\
\text { Yılları }\end{array}$ \\
\hline ALYAG & Altınyağ Kombinaları A.Ş. & Başarısız & 2017 \\
\hline AEFES & Anadolu Efes Biracılık ve Malt Sanayi A.Ş. & Başarılı & 2015 \\
\hline AVOD & AVOD Kurutulmuş Gıda ve Tarım Ürünleri A.Ş. & Başarılı & 2015 \\
\hline BANVT & Banvit Bandırma Vitaminli Yem Sanayi A.Ş. & Başarısız & 2015 \\
\hline CCOLA & Coca-Cola İçecek A.Ş. & Başarılı & 2015 \\
\hline DARDL & Dardanel Önentaş Gıda Sanayi A.Ş. & Başarısız & 2016 \\
\hline EKIZ & Ekiz Kimya Sanayi ve Ticaret A.Ş. & Başarısız & 2015 \\
\hline ERSU & Ersu Meyve ve Gıda Sanayi A.Ş. & Başarısız & 2015 \\
\hline FRIGO & Frigo-Pak Gıda Maddeleri Sanayi ve Ticaret A.Ş. & Başarısız & 2015 \\
\hline KRSAN & Karsusan Karadeniz Su Ürünleri Sanayi A.Ş. & Başarısız & 2017 \\
\hline KENT & Kent Gıda Maddeleri Sanayii ve Ticaret A.Ş. & Başarılı & 2015 \\
\hline KERVT & Kerevitaş Gıda Sanayi ve Ticaret A.Ş. & Başarısız & 2016 \\
\hline KNFRT & Konfrut Gıda Sanayi ve Ticaret A.Ş. & Başarılı & 2015 \\
\hline KRSTL & Kristal Kola ve Meşrubat Sanayi Ticaret A.Ş. & Başarılı & 2015 \\
\hline MERKO & Merko Gıda Sanayi ve Ticaret A.Ş. & Başarılı & 2015 \\
\hline MRTGG & Mert Gıda Giyim Sanayi ve Ticaret A.Ş. & Başarısız & 2016 \\
\hline OYLUM & Oylum Sınai Yatırımlar A.Ş. & Başarısız & 2017 \\
\hline PENGD & Penguen Gıda Sanayi A.Ş. & Başarılı & 2015 \\
\hline PETUN & Pınar Entegre Et ve Un Sanayi A.Ş. & Başarılı & 2015 \\
\hline PINSU & Pınar Su Sanayi ve Ticaret A.Ş. & Başarısız & 2017 \\
\hline PNSUT & Pınar Süt Mamulleri Sanayii A.Ş. & Başarılı & 2015 \\
\hline SELGD & Selçuk Gıda Endüstri İhracat İthalat A.Ş. & Başarılı & 2015 \\
\hline TATGD & Tat Gıda Sanayi A.Ş. & Başarılı & 2015 \\
\hline TKURU & Taze Kuru Gıda Sanayi ve Ticaret A.Ş. & Başarısız & 2015 \\
\hline TUKAS & Tukaş Gıda Sanayi ve Ticaret A.Ş. & Başarısız & 2014 \\
\hline TBORG & Türk Tuborg Bira ve Malt Sanayi A.Ş. & Başarılı & 2015 \\
\hline ULUUN & Ulusoy Un Sanayi ve Ticaret A.Ş. & Başarılı & 2015 \\
\hline ULKER & Ülker Bisküvi Sanayi A.Ş. & Başarılı & 2015 \\
\hline VANGD & Vanet Gıda Sanayi İç ve Dış Ticaret A.Ş. & Başarısız & 2012 \\
\hline KILER & Kiler Alışveriş Hizmetleri Gıda Sanayi ve Ticaret A.Ş. & Başarısız & 2015 \\
\hline
\end{tabular}

Çalışmada kriter olarak ise finansal oranlar kullanılmıştır. Kullanılan bu oranlar, finans literatüründe önemli olduğu kabul edilen ve yaygın olarak kullanılan oranlardır. Bu doğrultuda ele alınan 43 oran, finans ve muhasebe alanında uzmanlaşmış üç akademisyen ve bir muhasebe müdürü ile görüşülerek 10 finansal orana düşürülmüştür. Kriter olarak kullanılan finansal oranlar ve hesaplama formülleri Tablo 5'te verilmiştir.

Tablo 5. Finansal Başarısızlık Tahmininde Kullanılan Kriterler

\begin{tabular}{c|c}
\hline Kriterler (Finansal Oranlar) & Formülü \\
\hline Cari Oran & Dönen Varlıklar / Kısa Vadeli Yabancı Kaynaklar (KVYK) \\
Kaldıraç Oranı & Yabancı Kaynak Toplamı / Varlık (Aktif) Toplamı \\
KVYK Oranı & KVYK / Kaynak (Pasif) Toplamı \\
Stok Devir Hızı & Satışların Maliyeti / Ortalama Stok \\
Net Çalışma Sermayesi Devir Hızı & Net Satışlar / Dönen Varlıklar - KVYK \\
Aktif Devir Hızı & Net Satışlar / Varlık (Aktif) Toplamı \\
Öz Kaynak Kârııı̆ı & Net Kâr (VSK) / Öz Kaynaklar \\
Ekonomik Rantabilite & Faiz ve Vergiden Önceki Kâr (FVÖK) / Kaynak (Pasif) Toplamı \\
Aktif Getiri Oranı & Net Kâr (VSK) / Varlık (Aktif) Toplamı \\
Faaliyet Kâr Marjı & Faaliyet Kârı / Net Satışlar \\
\hline
\end{tabular}


Çalışmada ELECTRE TRI ve FLOWSORT yöntemleri ile tahmin amaçlandığı için, işletmelere ait kriter değerleri elde edilirken, başarı ve başarısızlık başlangıç tarihlerinden bir yıl öncesine ait veriler kullanılmıştır. İşletmelere ait kriter değerleri, yukarıda verilen formüller kullanılarak Excel paket programında hesaplanmıştır. Hesaplama sonrasında elde edilen başlangıç karar matrisi Ek 1'de verilmiştir.

ÇKKV yöntemlerinin doğru bir şekilde uygulanabilmesi için kriter yönünün de doğru bir şekilde fayda (maksimizasyon) veya maliyet (minimizasyon) şeklinde belirlenmesi ve buna göre uygulamanın yapılması gerekmektedir. Ancak literatürde yapılan çalışmalarda, örneğin, cari oranın kriter yönü maksimizasyon olarak alındığı tespit edilmiştir (Ömürbek ve Eren 2016: 13; Günay vd., 2018: 58-59; Yükçü ve Kaplanoğlu 2015: 604; Vatansever ve Aydın 2014: 169 vb). Fakat ideal cari oran değeri ülkemizde 2'dir. Bu oranın ne 2'nin altında ne de üstünde olması istenmektedir. Yani cari oran aslında yönsüz bir kriterdir. Ya da kaldıraç oranın ülkemizde 0,6 'nın altında olması yeterlidir. Bundan dolayı bu çalışmada; kriter yönlerinin doğru belirlenmesi için kullanılacak oranlara yeni fonksiyonlar tanımlanarak, Ek-1'deki ham verilerin tanımlanan fonksiyonlar ile yeni değerleri elde edilmiştir. Söz konusu her bir kriter için tanımlanan fonksiyon ve grafikleri aşağıda verilmiştir.

Grafik 1. Cari Oran için Tanımlanan Grafik ve Fonksiyon

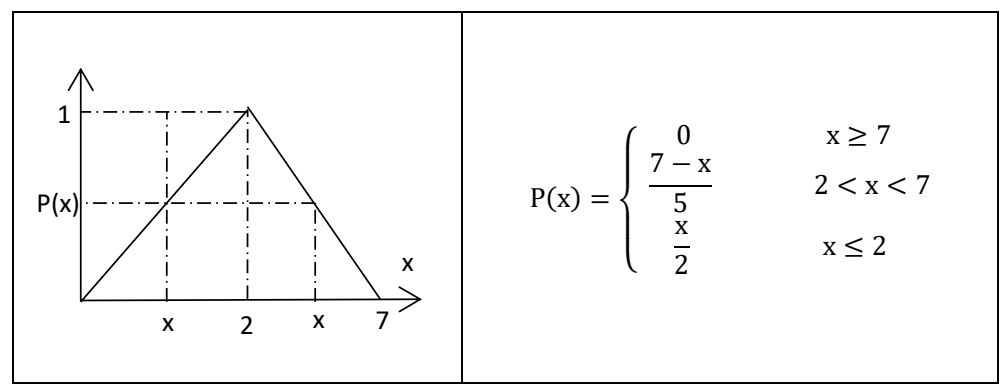

Grafik 2. Kaldıraç Oranı için Tanımlanan Grafik ve Fonksiyon

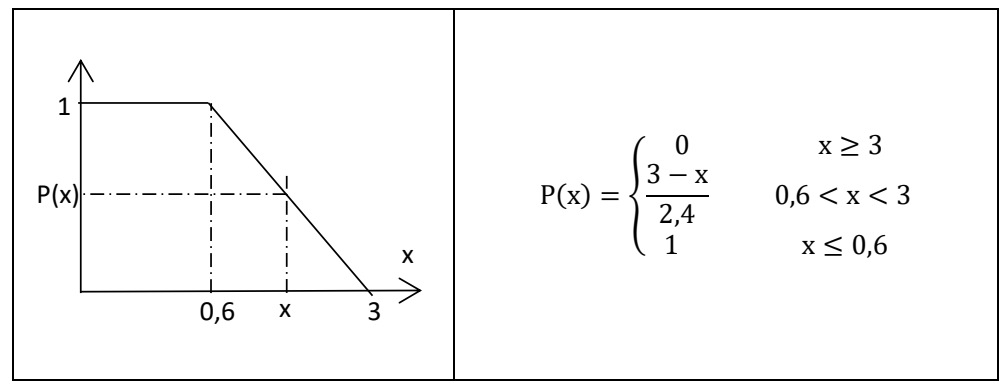


Grafik 3. KVYK Oranı için Tanımlanan Grafik ve Fonksiyon

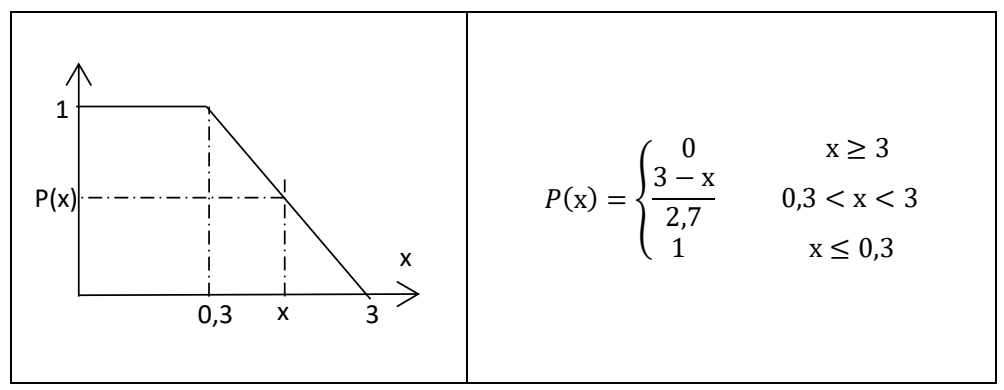

Grafik 4. Stok Devir Hızı, Aktif Devir Hızı için Tanımlanan Grafik ve Fonksiyon

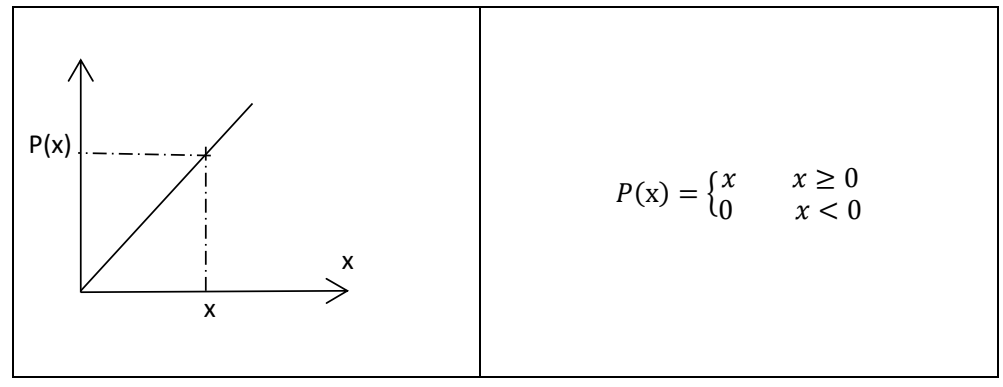

Grafik 5. Net Çalışma Sermayesi Devir Hızı, Öz Kaynak Kârlılığı, Ekonomik Rantabilite, Aktif Getiri Oranı, Faaliyet Kâr Marjı için Tanımlanan Grafik ve Fonksiyon

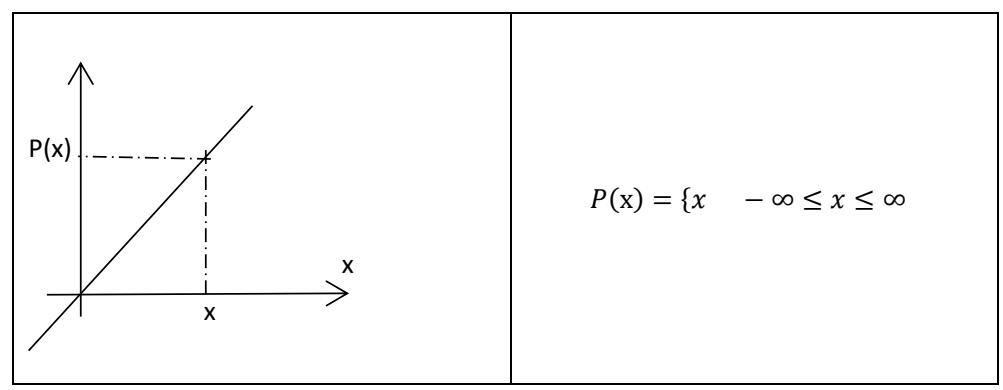

Yukarıda tanımlanan fonksiyonlar yardımıyla elde edilen yeni karar matrisi Ek 2'de verilmiştir. Tanımlanan bu fonksiyonlar ile tüm kriterlerin yönü maksimum hâle gelmiş olmaktadır. Cari oran, kaldıraç oranı ve KVYK oranı için tanımlanan fonksiyonların üst sınır değerleri EK-1'deki ilgili kritere ait en yüksek değerlerden oluşmaktadır.

\subsection{Kriter Ağırlıklarının Hesaplanması}

AHP yöntemi ile ağırlıklarının belirlenmesinde, finans ve muhasebe alanında uzmanlaşmış 3 akademisyen ve 1 muhasebe müdürü ile görüşülmüştür. Uzmanlara yapılan elektronik ankette, Saaty'nin 1-9 ölçeğini kullanarak uygulamanın yapıldığı sektör için kriterleri birbirleri ile kıyaslamaları istenmiştir. Uzman görüşlerinin tek bir grup kararı olarak birleştirilmesi sürecinde anket sonuçlarının geometrik ortalaması alınmıştır. Hesaplanan AHP ağırlık değerleri Tablo 6' da verilmiştir. 
Tablo 6. Kriter Ağırlıkları

\begin{tabular}{c|c}
\hline Kriter & Ağırlı̆ı \\
\hline Cari Oran & 0,06 \\
Kaldıraç Oranı & 0,04 \\
KVYK Oranı & 0,03 \\
Stok Devir Hızı & 0,07 \\
Net Çalışma Sermayesi Devir Hızı & 0,08 \\
Aktif Devir Hızı & 0,05 \\
Öz Kaynak Kârlılı̆ı & 0,17 \\
Ekonomik Rantabilite & 0,12 \\
Aktif Getiri Oranı & 0,13 \\
Faaliyet Kâr Marjı & 0,25 \\
\hline
\end{tabular}

Tablo 6 incelendiğinde; en yüksek ağırlığa sahip kriter \% 25 ile faaliyet kâr marjıyken, en düşük ağırlığa sahip kriter \% 3 ile KVYK oranıdır. Tutarlıık Oranı ise 0,0557 bulunmuştur. Bu değer $0,1^{\prime}$ den küçük olduğu için, ikili karşılaştırmaların tutarlı olduğu söylenebilir.

\subsection{ELECTRE TRI ile Uygulama}

Kriterler için sınır değerleri $\left(g_{j}\left(b_{h}\right)\right)$ denklem (1) yardımıyla bulunmuştur. Burada $\eta_{h}$ ve $\eta_{h+1}$ değerleri, sırasıyla finansal başarılı ve başarılı olmayan işletmelerin sayıları olan 15'tir. Daha sonra denklem (2) ve (3) kullanılarak her bir kritere ait eşik değerleri $\left(q_{j}\left(b_{h}\right), p_{j}\left(b_{h}\right)\right)$ hesaplanmış, elde edilen değerler Tablo 7'de verilmiştir.

Tablo 7. ELECTRE TRI Yöntemindeki Kriterlere Ait Sınır ve Eşik Değerleri

\begin{tabular}{|c|c|c|c|c|c|c|c|c|c|c|}
\hline $\mathbf{W}_{\mathbf{i}}$ & 0,06 & 0,04 & 0,03 & 0,07 & 0,08 & 0,05 & 0,17 & 0,12 & 0,13 & 0,25 \\
\hline \multirow[t]{2}{*}{$\begin{array}{l}\text { Kriter } \\
\text { yönü }\end{array}$} & Max & $\max$ & $\max$ & $\max$ & $\max$ & $\max$ & $\max$ & $\max$ & $\max$ & Max \\
\hline & 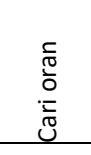 & 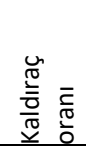 & $\begin{array}{l}\bar{c} \\
\overline{0} \\
\dot{0} \\
\underline{y} \\
\underline{z} \\
\end{array}$ & 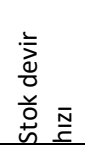 & 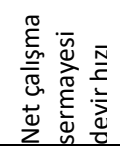 & 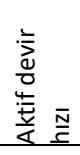 & 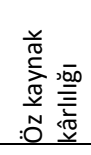 & 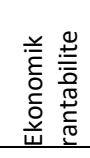 & 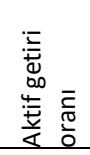 & 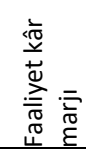 \\
\hline$g_{j}\left(b_{h}\right)$ & 1,207 & 1,872 & 1,840 & 13,29 & 6,347 & 1,942 & $-0,222$ & $-0,046$ & $-0,047$ & $-0,894$ \\
\hline$q_{j}\left(b_{h}\right)$ & 0,060 & 0,094 & 0,092 & 0,665 & 0,317 & 0,097 & $-0,011$ & $-0,002$ & $-0,002$ & $-0,045$ \\
\hline $\mathbf{p}_{j}\left(b_{h}\right)$ & 0,121 & 0,187 & 0,184 & 1,329 & 0,635 & 0,194 & $-0,022$ & $-0,005$ & $-0,005$ & $-0,089$ \\
\hline
\end{tabular}

Hesaplanan bu değerler çerçevesinde; kriter yönlerinin tamamı maksimizasyon olduğu için işletmelerin marjinal başarı indeks değerleri denklem (4), marjinal başarısızlık indeks değerleri denklem (5) kullanılarak hesaplanmıştır. Bu değerler ağırlıklarla çarpılarak toplam başarı ve başarısızık indeks değerleri bulunmuştur. Bulunan indeks değerleri skor kesme düzeyi $(\lambda)$ ile karşılaştırılarak işletmeler sınıflandırılmış, Tablo 8'deki sonuçlar elde edilmiştir. ELECTRE TRı yöntemi ile uygulama sonucunda 20 işletme başarılı sınıfına atanırken, 10 işletme başarısız sınıfına atanmıştır. 
Tablo 8. ELECRTE TRI Yöntemine Göre Sınıflandırma Sonuçları

\begin{tabular}{|c|c|c|c|}
\hline İşletmeler & $\sum_{j=1}^{m} w_{i} c_{j}\left(a_{i} b_{h}\right)$ & $\sum_{j=1}^{m} w_{i} c_{j}\left(b_{h} a_{i}\right)$ & $\begin{array}{c}\text { ELECTRE TRI Tah- } \\
\text { min SInıfı }\end{array}$ \\
\hline ALYAG & 0,49 & 0,51 & Başarısız \\
\hline AEFES & 0,66 & 0,33 & Başarılı \\
\hline AVOD & 0,75 & 0,25 & Başarılı \\
\hline BANVT & 0,54 & 0,33 & Başarılı \\
\hline CCOLA & 0,75 & 0,25 & Başarılı \\
\hline DARDL & 0,5 & 0,53 & Başarısız \\
\hline EKIZ & 0,73 & 0,26 & Başarılı \\
\hline ERSU & 0,66 & 0,33 & Başarılı \\
\hline FRIGO & 0,75 & 0,25 & Başarılı \\
\hline KRSAN & 0,42 & 0,58 & Başarısız \\
\hline KENT & 0,66 & 0,33 & Başarılı \\
\hline KERVT & 0,25 & 0,75 & Başarısız \\
\hline KNFRT & 0,66 & 0,33 & Başarılı \\
\hline KRSTL & 0,66 & 0,33 & Başarılı \\
\hline MERKO & 0,80 & 0,20 & Başarılı \\
\hline MRTGG & 0,17 & 0,82 & Başarısız \\
\hline OYLUM & 0,55 & 0,33 & Başarılı \\
\hline PENGD & 0,33 & 0,49 & Başarısız \\
\hline PETUN & 0,76 & 0,25 & Başarılı \\
\hline PINSU & 0,25 & 0,75 & Başarısız \\
\hline PNSUT & 0,75 & 0,25 & Başarılı \\
\hline SELGD & 0,66 & 0,33 & Başarılı \\
\hline TATGD & 0,66 & 0,33 & Başarılı \\
\hline TKURU & 0,25 & 0,75 & Başarısız \\
\hline TUKAS & 0,25 & 0,75 & Başarısız \\
\hline TBORG & 0,66 & 0,33 & Başarılı \\
\hline ULUUN & 0,8 & 0,25 & Başarılı \\
\hline ULKER & 0,66 & 0,33 & Başarılı \\
\hline VANGD & 0,17 & 0,83 & Başarısız \\
\hline KILER & 0,75 & 0,30 & Başarılı \\
\hline
\end{tabular}

\subsection{FLOWSORT Yöntemi ile Uygulama}

FLOWSORT yönteminde sınıfların sınırlandırıcı kesit değerleri KV'nin bilgi, deneyim ve tecrübesiyle belirlenmektedir. Ancak bazı zamanlarda KV'nin, tam bilgiye ve kesin yargıya sahip olmadığı durumlar söz konusudur. Bu tür durumlarda öncelikle karar matrisine normalizasyon işlemi yapılarak her karar matrisi elemanının 0 ile 1 arasında değer alması sağlanabilmekte, bu da sınıfların kesit değerlerinin de 0-1 ölçeği içerisinde tanımlanmasına olanak sağlamaktadır (Es vd., 2016: 167). Bu çalışmada da öncelikle Ek 2'deki karar matrisi verileri denklem (20) ile kriter bazında normalize edilmiştir. Normalize edilen karar matrisi Ek-3'te verilmiştir.

$$
a_{i j}=\frac{a_{0 j}-a_{j_{\min }}}{a_{j_{\text {maks }}}-a_{j_{\text {min }}}} \quad i=1,2, \ldots, 30 \quad j=1,2, \ldots, 10
$$

Burada $a_{i j}$ i. karar alternatifinin j. kriter için normalize değerini, $a_{0 j}$ orijinal veriyi temsil etmektedir. $a_{j_{\min }}$ ve $a_{j_{m a k s}}$ ise, kriter bazında maksimum ve minimum değeri ifade etmektedir.

Normalizasyon işlemi ile karar matrisinin tüm elemanlarının 0-1 aralığında değer alması sağlandığı ve alternatifler başarılı ve başarısız olmak üzere iki sınıfa ayrılacağı için tüm kriterler için kesit değerleri 1 üzerinden iki eşit parçaya bölünerek belirlenmiş ve Tablo 9'da verilmiştir. 
Tablo 9. FLOWSORT Yöntemindeki Sınıfların Sınırlandırıcı Kesit Değerleri

\begin{tabular}{|c|c|c|c|c|c|c|c|c|c|c|}
\hline $\mathrm{R}$ & $\begin{array}{l}\frac{5}{10} \\
\frac{10}{2} \\
\frac{1}{0} \\
\end{array}$ & $\begin{array}{l}\bar{c} \\
\frac{\pi}{0} \\
0 \\
0 \\
\frac{\pi}{0} \\
\frac{0}{\pi} \\
\underline{\pi} \\
\end{array}$ & $\begin{array}{l}\bar{\Sigma} \\
\frac{\pi}{0} \\
\overline{0} \\
\frac{y}{3} \\
\underline{z} \\
\end{array}$ & 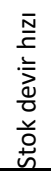 & 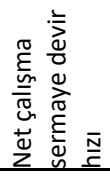 & 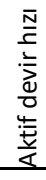 & 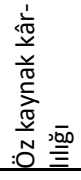 & 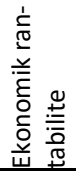 & 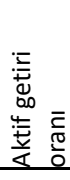 & 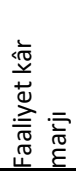 \\
\hline$r_{1}$ & 1 & 1 & 1 & 1 & 1 & 1 & 1 & 1 & 1 & 1 \\
\hline$r_{2}$ & 0,5 & 0,5 & 0,5 & 0,5 & 0,5 & 0,5 & 0,5 & 0,5 & 0,5 & 0,5 \\
\hline$r_{3}$ & 0 & 0 & 0 & 0 & 0 & 0 & 0 & 0 & 0 & 0 \\
\hline
\end{tabular}

Sınırlandırıcı kesit değerlerinin belirlenmesinden sonra veriler VISUAL PROMETHEE paket programına girilerek tercih fonksiyonlarının tipi ve parametre değerleri program aracılığıyla elde edilmiştir. Program tüm kriterler için 5. tip doğrusal tercih fonksiyonunu vermiştir. Bunun karar matrisi verileri elde edilirken/dönüştürülürken de doğrusal fonksiyonların kullanılmasından kaynaklandığı düşünülmektedir.

Daha sonra her işletme için kesit değerleri ile ikili karşılaştırmalar yapılarak, tercih fonksiyonu değerleri ve tercih dereceleri elde edilmiştir. Örneğin ALYAG işletmesi için bu işlemler açıklanacak olursa; ALYAG'ın $r_{1}^{\prime}$ 'e cari oran kriterinde bir üstünlüğü olmadığı (yani $0,22<1$ ) için tercih fonksiyonu değeri $P$ (ALYAG, $r_{1}$ )=0'dır. $r_{1}{ }^{\prime}$ in ALYAG'a üstünlüğü olduğundan aradaki fark $(1-0,22=0,78)$ doğrusal tercih fonksiyonunda yerine koyularak $P\left(r_{1}, A L Y A G\right)=1$ değeri elde edilmiştir. Benzer ikili karşılaştırmalar diğer kesit değerleri için de uygulanmıştır. Son olarak elde edilen tercih fonksiyonu değerleri kriter ağırlıkları ile çarpılarak ALYAG için tercih dereceleri elde edilmiş, sonuçlar Tablo 10' da verilmiştir. Benzer işlemler diğer işletmeler için de yapılmış, ancak hazırlanan tablolar çok fazla yer kapladığı için çalışmada yer verilmemiştir.

Tablo 10. ALYAG İçin Tercih Fonksiyonu Değerleri ve Tercih Dereceleri

\begin{tabular}{|c|c|c|c|c|c|c|c|c|c|c|c|}
\hline & $\begin{array}{l}\delta \\
\delta \\
\frac{\delta}{\delta} \\
\frac{1}{0}\end{array}$ & 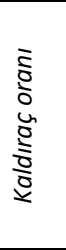 & 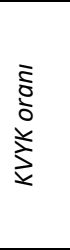 & 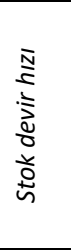 & 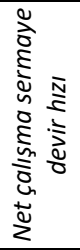 & 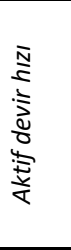 & 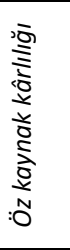 & 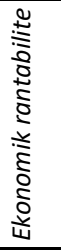 & 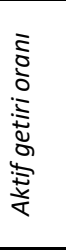 & 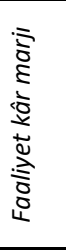 & 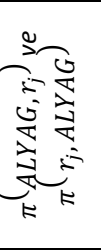 \\
\hline $\mathbf{w}_{\mathrm{j}}$ & 0,06 & 0,04 & 0,03 & 0,07 & 0,08 & 0,05 & 0,17 & 0,12 & 0,13 & 0,25 & \\
\hline ALYAG & 0,22 & 1 & 0,85 & 1 & 0,33 & 0,24 & 0,71 & 0,55 & 0,56 & 0,98 & \\
\hline$P\left(A L Y A G, r_{1}\right)$ & 0 & 0 & 0 & 0 & 0 & 0 & 0 & 0 & 0 & 0 & 0 \\
\hline$P\left(r_{1}, A L Y A G\right)$ & 1 & 0 & 0 & 0 & 1 & 1 & 0,84 & 1 & 0,93 & 0 & 0,46 \\
\hline$P\left(A L Y A G, r_{2}\right)$ & 0 & 1 & 1 & 1 & 0 & 0 & 0,23 & 0 & 0 & 1 & 0,42 \\
\hline$P\left(r_{2}, A L Y A G\right)$ & 0,18 & 0 & 0 & 0 & 0 & 0,27 & 0 & 0 & 0 & 0 & 0,02 \\
\hline$P\left(A L Y A G, r_{3}\right)$ & 0 & 1 & 1 & 1 & 0,76 & 0,22 & 1 & 1 & 1 & 1 & 0,88 \\
\hline$P\left(r_{3}, A L Y A G\right)$ & 0 & 0 & 0 & 0 & 0 & 0 & 0 & 0 & 0 & 0 & 0 \\
\hline
\end{tabular}

Son olarak (12), (13) ve (14) kullanılarak pozitif, negatif ve net akım değerleri hesaplanıp, (15), (16) ve (17) ile sınıflandırmalar yapılmıştır. Gerçekleştirilen atamalar Tablo 11 'de verilmiştir. 
Tablo 11. FLOWSORT Yöntemine Göre Sınıflandırma Sonuçları

\begin{tabular}{|c|c|c|c|c|c|c|}
\hline & & $r_{1}$ & $r_{2}$ & $r_{3}$ & $a_{i}$ & $C\left(a_{i}\right)$ \\
\hline \multirow{3}{*}{ ALYAG } & $\overline{\phi^{+}}$ & 0,82 & 0,34 & 0 & 0,43 & Başarılı \\
\hline & $\phi^{-}$ & 0 & 0,47 & 0,96 & 0,16 & Başarılı \\
\hline & $\phi^{\text {net }}$ & 0,82 & $-0,1$ & -1 & 0,27 & Başarılı \\
\hline \multirow{3}{*}{ AEFES } & $\phi^{+}$ & 0,8 & 0,35 & 0 & 0,44 & Başarılı \\
\hline & $\phi$ & 0 & 0,48 & 0,96 & 0,18 & Başarılı \\
\hline & $\phi^{\text {net }}$ & 0,8 & $-0,1$ & -1 & 0,27 & Başarılı \\
\hline \multirow{3}{*}{ AVOD } & $\phi^{+}$ & 0,8 & 0,35 & 0 & 0,44 & Başarılı \\
\hline & $\phi$ & 0 & 0,47 & 0,96 & 0,16 & Başarılı \\
\hline & $\phi^{\text {net }}$ & 0,8 & $-0,1$ & -1 & 0,28 & Başarılı \\
\hline \multirow{3}{*}{ BANVT } & $\phi^{+}$ & 0,9 & 0,36 & 0 & 0,39 & Başarılı \\
\hline & $\phi^{-}$ & 0 & 0,44 & 0,95 & 0,23 & Başarılı \\
\hline & $\phi^{\text {net }}$ & 0,9 & $-0,1$ & -1 & 0,16 & Başarılı \\
\hline \multirow{3}{*}{ CCOLA } & $\phi^{+}$ & 0,8 & 0,34 & 0 & 0,5 & Başarılı \\
\hline & $\phi$ & 0 & 0,54 & 0,96 & 0,12 & Başarılı \\
\hline & $\phi^{\text {net }}$ & 0,8 & $-0,2$ & -1 & 0,38 & Başarılı \\
\hline \multirow{3}{*}{ DARDL } & $\phi^{+}$ & 0,9 & 0,45 & 0 & 0,35 & Başarısız \\
\hline & $\phi^{-}$ & 0 & 0,48 & 0,87 & 0,31 & Başarılı \\
\hline & $\phi^{\text {net }}$ & 0,9 & -0 & $-0,9$ & 0,04 & Başarılı \\
\hline \multirow{3}{*}{ EKIZ } & $\phi^{+}$ & 0,8 & 0,35 & 0 & 0,44 & Başarılı \\
\hline & $\phi$ & 0 & 0,48 & 0,96 & 0,17 & Başarılı \\
\hline & $\phi^{\text {net }}$ & 0,8 & $-0,1$ & -1 & 0,27 & Başarılı \\
\hline \multirow{3}{*}{ ERSU } & $\phi^{+}$ & 0,8 & 0,37 & 0 & 0,43 & Başarılı \\
\hline & $\phi$ & 0 & 0,47 & 0,96 & 0,2 & Başarılı \\
\hline & $\phi^{\text {net }}$ & 0,8 & $-0,1$ & -1 & 0,23 & Başarılı \\
\hline \multirow{3}{*}{ FRIGO } & $\phi^{+}$ & 0,9 & 0,36 & 0 & 0,42 & Başarılı \\
\hline & $\phi$ & 0 & 0,46 & 0,96 & 0,21 & Başarılı \\
\hline & $\phi^{\text {net }}$ & 0,9 & $-0,1$ & -1 & 0,21 & Başarılı \\
\hline \multirow{3}{*}{ KRSAN } & $\phi^{+}$ & 0,9 & 0,48 & 0 & 0,23 & Başarısız \\
\hline & $\phi$ & 0 & 0,38 & 0,85 & 0,41 & Başarısız \\
\hline & $\phi^{\text {net }}$ & 0,9 & 0,1 & $-0,9$ & $-0,2$ & Başarısız \\
\hline \multirow{3}{*}{ KENT } & $\phi^{+}$ & 0,8 & 0,33 & 0 & 0,48 & Başarılı \\
\hline & $\phi$ & 0 & 0,5 & 0,98 & 0,13 & Başarılı \\
\hline & $\phi^{\text {net }}$ & 0,8 & $-0,2$ & -1 & 0,35 & Başarılı \\
\hline \multirow{3}{*}{ KERVT } & $\phi^{+}$ & 0,9 & 0,42 & 0 & 0,32 & Başarısız \\
\hline & $\phi$ & 0 & 0,43 & 0,88 & 0,31 & Başarılı \\
\hline & $\phi^{\text {net }}$ & 0,9 & -0 & $-0,9$ & 0,01 & Başarılı \\
\hline \multirow{3}{*}{ KNFRT } & $\phi^{+}$ & 0,8 & 0,36 & 0 & 0,52 & Başarılı \\
\hline & $\phi$ & 0 & 0,57 & 0,95 & 0,13 & Başarılı \\
\hline & $\phi^{\text {net }}$ & 0,8 & $-0,2$ & -1 & 0,39 & Başarılı \\
\hline \multirow{3}{*}{ KRSTL } & $\phi^{+}$ & 0,8 & 0,35 & 0 & 0,44 & Başarılı \\
\hline & $\phi$ & 0 & 0,48 & 0,96 & 0,16 & Başarılı \\
\hline & $\phi^{\text {net }}$ & 0,8 & $-0,1$ & -1 & 0,28 & Başarılı \\
\hline \multirow{3}{*}{ MERKO } & $\phi^{+}$ & 0,7 & 0,34 & 0 & 0,56 & Başarılı \\
\hline & $\phi$ & 0 & 0,58 & 0,98 & 0,07 & Başarılı \\
\hline & $\phi^{\text {net }}$ & 0,7 & $-0,2$ & -1 & 0,49 & Başarılı \\
\hline
\end{tabular}

\begin{tabular}{|c|c|c|c|c|c|c|}
\hline & & $r_{1}$ & $r_{2}$ & $r_{3}$ & $a_{i}$ & $c\left(a_{i}\right)$ \\
\hline \multirow{3}{*}{ MRTGG } & $\phi^{+}$ & 0,9 & 0,47 & 0 & 0,23 & Başarısız \\
\hline & $\phi^{-}$ & 0 & 0,41 & 0,82 & 0,37 & Başarılı \\
\hline & $\phi^{\text {net }}$ & 0,9 & 0,06 & $-0,8$ & $-0,1$ & Başarısız \\
\hline \multirow{3}{*}{ OYLUM } & $\phi^{+}$ & 0,9 & 0,35 & 0 & 0,41 & Başarılı \\
\hline & $\phi$ & 0 & 0,46 & 0,95 & 0,21 & Başarılı \\
\hline & $\phi^{\text {net }}$ & 0,9 & $-0,1$ & -1 & 0,21 & Başarılı \\
\hline \multirow{3}{*}{ PENGD } & $\phi^{+}$ & 0,9 & 0,36 & 0 & 0,44 & Başarılı \\
\hline & $\phi^{-}$ & 0 & 0,48 & 0,96 & 0,22 & Başarılı \\
\hline & $\phi^{\text {net }}$ & 0,9 & $-0,1$ & -1 & 0,22 & Başarılı \\
\hline \multirow{3}{*}{ PETUN } & $\phi^{+}$ & 0,7 & 0,33 & 0 & 0,52 & Başarılı \\
\hline & $\phi^{-}$ & 0 & 0,53 & 0,99 & 0,07 & Başarılı \\
\hline & $\phi^{\text {net }}$ & 0,7 & $-0,2$ & -1 & 0,45 & Başarılı \\
\hline \multirow{4}{*}{ PINSU } & & & & & & Başarılı/ \\
\hline & $\Phi^{\top}$ & & $0,3 /$ & 0 & 0,37 & Başarısız \\
\hline & $\phi^{-}$ & 0 & 0,44 & 0,93 & 0,26 & Başarılı \\
\hline & $\phi^{\text {net }}$ & 0,9 & $-0,1$ & $-0,9$ & 0,11 & Başarılı \\
\hline \multirow{3}{*}{ PNSUT } & $\phi^{+}$ & 0,8 & 0,33 & 0 & 0,5 & Başarılı \\
\hline & $\phi^{-}$ & 0 & 0,53 & 0,98 & 0,08 & Başarılı \\
\hline & $\phi^{\text {net }}$ & 0,8 & $-0,2$ & -1 & 0,42 & Başarılı \\
\hline \multirow{3}{*}{ SELGD } & $\phi^{+}$ & 0,8 & 0,35 & 0 & 0,44 & Başarılı \\
\hline & $\phi$ & 0 & 0,48 & 0,96 & 0,16 & Başarılı \\
\hline & $\phi^{\text {net }}$ & 0,8 & $-0,1$ & -1 & 0,27 & Başarılı \\
\hline \multirow{3}{*}{ TATGD } & $\phi^{+}$ & 0,8 & 0,35 & 0 & 0,53 & Başarılı \\
\hline & $\phi$ & 0 & 0,56 & 0,97 & 0,09 & Başarılı \\
\hline & $\phi^{\text {net }}$ & 0,8 & $-0,2$ & -1 & 0,43 & Başarılı \\
\hline \multirow{3}{*}{ TKURU } & $\phi^{+}$ & 0,9 & 0,37 & 0 & 0,32 & Başarısız \\
\hline & $\phi$ & 0 & 0,45 & 0,87 & 0,25 & Başarılı \\
\hline & $\phi^{\text {net }}$ & 0,9 & $-0,1$ & $-0,9$ & 0,07 & Başarılı \\
\hline \multirow{3}{*}{ TUKAS } & $\phi^{+}$ & 0,9 & 0,39 & 0 & 0,35 & Başarısız \\
\hline & $\phi$ & 0 & 0,45 & 0,91 & 0,26 & Başarılı \\
\hline & $\phi^{\text {net }}$ & 0,9 & $-0,1$ & $-0,9$ & 0,09 & Başarılı \\
\hline \multirow{3}{*}{ TBORG } & $\phi^{+}$ & 0,7 & 0,34 & 0 & 0,54 & Başarılı \\
\hline & $\phi$ & 0 & 0,58 & 0,96 & 0,08 & Başarılı \\
\hline & $\phi^{\text {net }}$ & 0,7 & $-0,2$ & -1 & 0,46 & Başarılı \\
\hline \multirow{3}{*}{ ULUUN } & $\phi^{+}$ & 0,8 & 0,34 & 0 & 0,46 & Başarılı \\
\hline & $\phi^{-}$ & 0 & 0,48 & 0,98 & 0,13 & Başarılı \\
\hline & $\phi^{\text {net }}$ & 0,8 & $-0,1$ & -1 & 0,33 & Başarılı \\
\hline \multirow{3}{*}{ ULKER } & $\phi^{+}$ & 0,8 & 0,34 & 0 & 0,5 & Başarılı \\
\hline & $\phi^{-}$ & 0 & 0,52 & 0,98 & 0,09 & Başarılı \\
\hline & $\phi^{\text {net }}$ & 0,8 & $-0,2$ & -1 & 0,41 & Başarılı \\
\hline \multirow{3}{*}{ VANGD } & $\phi^{+}$ & 0,9 & 0,37 & 0 & 0,3 & Başarısız \\
\hline & $\phi$ & 0 & 0,45 & 0,85 & 0,26 & Başarılı \\
\hline & $\phi^{\text {net }}$ & 0,9 & $-0,1$ & $-0,9$ & 0,05 & Başarılı \\
\hline \multirow{3}{*}{ KILER } & $\phi^{+}$ & 0,9 & 0,36 & 0 & 0,42 & Başarılı \\
\hline & $\phi$ & 0 & 0,46 & 0,97 & 0,21 & Başarılı \\
\hline & $\phi^{\text {net }}$ & 0,9 & $-0,1$ & -1 & 0,22 & Başarılı \\
\hline
\end{tabular}

Atamalar sonucunda 22 işletme pozitif ve negatif, 8 işletme net akıma göre sınıflara atanmıştır. 28 işletme başarılı sınıfına atanırken, 2 işletme başarısız sınıfına atanmıştır. 


\section{Sonuç ve Öneriler}

Bu çalışmada, ELECTRE TRI ve FLOWSORT çok kriterli sınıflandırma yöntemleri kullanılarak finansal başarısızlık tahminlemesi yapılmıştır. Yöntemin uygulamasında BiST'te işlem gören 30 gıda, içki ve tütün işletmesinin 2010-2017 yıllarındaki verileri kullanıımıştır. İ̧̧letmeler öncelikle finans alanında kabul gören başarısızık kriterleri çerçevesinde başarılı/başarısız olarak sınıflandırılarak bir öngörü seti elde edilmiştir.

Öngörü setinin oluşturulmasından sonra, yöntemlerin uygulanması sürecinde veri olarak finansal oranlar kullanılmıştır. Finansal oranlar işletmelerin şu anki durumları ve gelecekteki ön değerlendirmelerinde KV'lere fikir veren oranlardır. Söz konusu oranlar kullanılan yöntemlerde kriter olarak ele alınmıştır. Kriterlerin belirlenmesinde ise uzman görüşünden yararlanılmıştır.

Çalışmada kullanılan yöntemlerin uygulanabilmesi için kriter ağırlıkları/önem düzeyleri bilinmelidir. Kriterlerden hangisinin daha fazla öneme sahip olduğunu belirlemek için AHP yöntemi kullanılmıştır. AHP yönteminin uygulanması sürecinde 4 uzmanın görüşleri alınarak her bir kriter için ikili karşılaştırmalar yapılmıştır. Uzman görüşleri çerçevesinde \%25 ile en fazla ağırlığa sahip olan kriter faaliyet kâr marjı olmuştur. Bunu sırasıyla; \%17 ile öz kaynak kârlıı̆̆ı, \%13 ile aktif getiri oranı, \%12 ile ekonomik rantabilite, \% 8 ile net çalışma sermayesi devir hızı, \%7 ile stok devir hızı, \%6 ile cari oran, \%5 ile aktif devir hızı, \%4 ile kaldıraç oranı izlemektedir. En düşük orana sahip kriter ise \%3 ile KVYK oranı olmuştur. Bu ağırlık değerlerinden sonuçtan hareketle sektördeki işletmelerin başarılı ve başarısız olarak sınıflandırılmasında; faaliyet kâr marjı, öz kaynak kârlılığı, aktif getiri oranı ve ekonomik rantabilitenin ön plandaki kriterler olduğu görülmektedir. Ancak, AHP yöntemi ile elde edilen kriter ağırlıkları, öznel değerlendirmelere dayandığı için farklı uzman görüşlerinde farklı sonuçlar elde edilebilir.

ÇKKV yöntemlerinin doğası gereği belirlenen kriterlerin yönlerinin bilinmesi gerekmektedir. Ancak kullanılan kriterlerden cari oranın 2 olması en ideal değerdir. Bunun üstü ve altı bu kriter için iyi bir değer değildir. Bu sebeple bu kriter yönsüz bir kriterdir. Benzer şekilde KVYK oranı ve kaldıraç oranının da belli bir düzeyin altında olması yeterli olarak görülmektedir. Bundan dolayı yöntemler uygulanmadan önce bu çalışmada kriter yönlerinin belirlenebildiği fonksiyonlar tanımlanmıştır.

Tablo 12, kullanılan yöntemlerin karşılaştırmalı olarak tahmin sonuçlarını göstermektedir. ELECTRE TRI yöntemi sonuçlarına göre, toplam 30 işletme içinden 7 işletme yanlış olarak sınıflandırılmıştır. Yöntemin doğru sınıflandırma oranı \%77, yanlış sınıflandırma oranı \%23'tür. Başarılı işletmelerden 1 işletme (PENGD) başarısız olarak sınıflandırılmıştır. Dolayısıyla başarılı işletmeleri doğru sınıflandırma oranı \%93, yanlış sınıflandırma oranı \%7'dir. Başarısız işletmelerden ise 6 işletme (BANVT, EKIZ, ERSU, FRIGO, OYLUM, KILER) başarılı olarak sınıflandırılmıştır. Başarısız işletmelerin doğru sınıflandırma oranı \%60, yanlış sınıflandırma oranı ise \%40 olarak gerçekleşmiştir.

FLOWSORT yönteminde ise 30 işletme içinden 13 işletme yanlış olarak sınıflandırılmıştır. Yöntemin doğru sınıflandırma oranı \%57, yanlış sınıflandırma oranı ise \%43'tür. Yöntem, başarılı işletmelerin tümünü doğru sınıflandırmıştır. Dolayısıyla başarılı işletmelerin doğru sınıflandırma oranı \%100'dür. Başarısız işletmelerden ise 13 tanesini başarılı olarak (ALYAG, BANVT, DARDL, KERVT, EKIZ, ERSU, FRIGO, OYLUM, PINSU, TKURU, TUKAS, VANGD, KILER) sınıflandırmıştır. Başarısız işletmeleri doğru sınıflandırma oranı \%13, yanlış sınıflandırma oranı ise \%87'dir.

Elde edilen sonuçlar doğrultusunda ELECTRE TRI yönteminin, FLOWSORT yöntemine göre daha iyi sonuç verdiği söylenebilir. Her iki yöntemde de BANVT, EKIZ, ERSU, FRIGO, OYLUM ve 
KILER işletmeleri başarısızken başarılı bulunmuştur. Yanlış olarak sınıflandırılan işletmeler detaylı incelendiğinde çoğunlukla, en az üst üste 3 yıl zarar etmiş olma kriterine uyan işletmelerden oluştuğu görülmektedir. Bu sebeple öngörü setinin oluşturulması sürecinde "3 yıl zarar etmiş olma" kriteri çıkarılırsa daha başarılı tahmin sonuçlarının elde edileceği düşünülmektedir.

Tablo 12. ELECTRE TRI ve FLOWSORT Yöntemlerinin Karşılaştırmalı Tahmin Sonuçları

\begin{tabular}{|c|c|c|c|}
\hline İşletmeler & $\begin{array}{l}\text { Doğru Kabul Edi- } \\
\text { len Sınıf }\end{array}$ & $\begin{array}{c}\text { ELECTRE TRI Tahmin So- } \\
\text { nucu }\end{array}$ & $\begin{array}{c}\text { FLOWSORT Tahmin } \\
\text { Sonucu }\end{array}$ \\
\hline ALYAG & Başarısız & Başarısız & Başarılı** \\
\hline AEFES & Başarılı & Başarılı & Başarılı \\
\hline AVOD & Başarılı & Başarılı & Başarılı \\
\hline BANVT & Başarısız & Başarılı** & Başarılı** \\
\hline CCOLA & Başarılı & Başarılı & Başarılı \\
\hline DARDL & Başarısız & Başarısız & Başarılı** \\
\hline$E K I Z$ & Başarısız & Başarılı** & Başarılı** \\
\hline ERSU & Başarısız & Başarılı** & Başarılı** \\
\hline FRIGO & Başarısız & Başarılı** & Başarılı** \\
\hline KRSAN & Başarısız & Başarısız & Başarısız \\
\hline KENT & Başarılı & Başarılı & Başarılı \\
\hline KERVT & Başarısız & Başarısız & Başarılı** \\
\hline KNFRT & Başarılı & Başarılı & Başarılı \\
\hline KRSTL & Başarılı & Başarılı & Başarılı \\
\hline MERKO & Başarılı & Başarılı & Başarılı \\
\hline MRTGG & Başarısız & Başarısız & Başarısız \\
\hline OYLUM & Başarısız & Başarılı & Başarılı \\
\hline PENGD & Başarılı & Başarısız** & Başarılı \\
\hline PETUN & Başarılı & Başarılı & Başarılı \\
\hline PINSU & Başarısız & Başarısız & Başarılı** \\
\hline PNSUT & Başarılı & Başarılı & Başarılı \\
\hline SELGD & Başarılı & Başarılı & Başarılı \\
\hline TATGD & Başarılı & Başarılı & Başarılı \\
\hline TKURU & Başarısız & Başarısız & Başarılı** \\
\hline TUKAS & Başarısız & Başarısız & Başarılı** \\
\hline TBORG & Başarılı & Başarılı & Başarılı \\
\hline ULUUN & Başarılı & Başarılı & Başarılı \\
\hline ULKER & Başarılı & Başarılı & Başarılı \\
\hline VANGD & Başarısız & Başarısız & Başarıı** \\
\hline KILER & Başarısız & Başarılı** & Başarılı** \\
\hline
\end{tabular}

Finans alanında bugüne kadar yapılan ÇKKV çalışmalarında kullanılan finansal oranların belli bir düzeyin altındaki ya da üstündeki değerlerin göz ardı edilmesi ve bu değerlere direk artan ya da azalan denilmesinin oranların açıklanması doğrultusunda yanlış olduğu düşünülmektedir. Bu çalışmada tanımlanan fonksiyonların; finans alanında yapılacak yeni ÇKKV çalışmalarına fikir verebileceği, ortaya koyulan bu yeni bakış açısı ile literatüre katkı sağlandığı düşünülmektedir.

Ele alınan probleme, UTADIS, AHPSORT gibi diğer çok kriterli sınıflandırma ve istatistiksel yöntemlerin uygulanması, daha iyi fonksiyon tanımlamalarının yapılması veya nicel kriterlerin yanında; yöneticilerin iş tecrübesi, işletmenin pazar alanı, rekabet gücü gibi nitel kriterlerin dikkate alındığı uygulamalarla ileride daha iyi çözümler önerilebileceği düşünülmektedir. 


\section{Eskişehir Osmangazi Üniversitesi IïB Dergisi}

\section{Kaynaklar}

Ahn, B. S.; Cho, S. S.; Kim, C. Y. (2000), "The Integrated Methodology of Rough Set Theory and Artificial Neural Network for Business Failure Prediction", Expert Systems with Applications, Vol. 18, No. 2: 65-74.

Akkaya, Gökay; Turanoğlu, Betül; Öztaş, Sinan (2015), “An Integrated Fuzzy AHP and Fuzzy MOORA Approach to The Problem of Industrial Engineering Sector Choosing”, Expert Systems with Applications, Vol. 42, No. 24: 9565-9573.

Aktaş, Ramazan (1997), Mali Başarısızık (Işsletme Riski) Tahmin Modelleri, Ankara: Türkiye İş Bankası Kültür Yayınları.

Altman, Edward I.; Narayanan Paul (1997), “An International Survey of Business Failure”, Financial Markets, Institutions \& Instruments, Vol. 6, No. 2: 1-57.

Altman, Edward. I. (1968), "Financial Ratios, Discriminant Analysis and the Prediction of Corporate Bankruptcy", The Journal of Finance, Vol. 23, No. 4: 589-609.

Beaver, William H. (1966), "Financial Ratios as Predictors of Failure”, Journal of Accounting Research, 71-111.

Bolak, Mehmet (1998), İşletme Finansı, İstanbul: Birsen Yayınevi.

Brabazon, Anthony; Matthews, Robin; O'Neill, Michael; Ryan, Conor (2002, July), Grammatical Evolution and Corporate Failure Prediction, in Proceedings of the 4th Annual Conference on Genetic and Evolutionary Computation, Morgan Kaufmann Publishers Inc: 1011-1018

Brans, Jean P.; Mareschal, Bertrand (2005), PROMETHEE Methods, Multiple Criteria Decision Analysis: State of The Art Surveys, (Editörler: J. Figueira, S. Greco., M. Ehrgott), New York, Springer.

Can, Şefika; Arıkan, Feyzan (2014), "Bir Savunma Sanayi Firmasında Çok Kriterli Alt Yüklenici Seçim Problemi ve Çözümü”, Gazi Üniversitesi Mühendislik-Mimarlık Fakültesi Dergisi, Cilt. 29, Sayı. 4: 645-654.

Campos, Ana Carolina Scanavachi Moreira; Mareschal, Teixeira de Almeida, Bertrand Adiel (2015), “Fuzzy FlowSort: An integration of the FlowSort method and Fuzzy Set Theory for decision making on the basis of inaccurate quantitative data", Information Sciences, Vol. 293: 115-124

Dağ, Sündüs; Yıldırım, Bahadır F. (2015), Operasyonel, Yönetsel ve Stratejik Problemlerin Çözümünde Çok Kriterli Karar Verme Yöntemleri, Editörler: B. F. Yıldııı; E. Önder, Bursa: Dora Basım-Yayın Dağıtım.

Dağdeviren, Metin; Eren, Tamer (2001), “Tedarikçi Firma Seçiminde Analitik Hiyerarşi Prosesi ve 0-1 Hedef Programlama Yöntemlerinin Kullanılması”, Gazi Üniversitesi Mühendislik-Mimarlık Fakültesi Dergisi, Cilt. 16, Sayı. 1: 41-52.

Dimitras, Augustinos I.; Zanakis, Stelios H.; Zopounidis, Constantin (1996), "A Survey of Business Failures with An Emphasis on Prediction Methods and Industrial Applications", European Journal of Operational Research, Vol. 90, No. 3: 487-513.

Doğrul, Ümit (2009), Finansal Başarısızlık ve Finansal Başarısızlığın Tahmini: Hisse Senetleri İstanbul Menkul Kıymetler Borsasında İşlem Gören Sınai İşletmeleri Üzerinde Bir Uygulama, Mersin Üniversitesi, Sosyal Bilimler Enstitüsü, İşletme Anabilim Dalı (Yayımlanmış Yüksek Lisans Tezi), Mersin.

Doumpos, Michael; Zopounidis, Constantin (2002), "Multi-Criteria Classification Methods in Financial and Banking Decisions", International Transactions in Operational Research, Vol. 9, No. 5: 567-581.

Ercan, Metin K.; Ban, Ünsal (2005), Değere Dayalı Işletme Finansı Finansal Yönetim, Ankara: Gazi Kitapevi.

Es, Hüseyin Avni; Hamzaçebi, Coşkun; Oktay Fırat, Seniye Ümit (2016), “FLOWSORT Yöntemi ile Gelişmiş Ülkerin Ar-Ge Faaliyetlerine Göre Sınıflandırılması”, 3. Uluslararası Yönetim Bilişim Sistemleri Konferansı, İzmir: Akıllı Teknoloji ve Akıllı Yönetim, 163-173.

Es, Hüseyin Avni; Hamzaçebi, Coşkun; Oktay Fırat, Seniye Ümit (2017), “Bulanık Flowsort Yöntemiyle Türkiye'de Illerin Eğitim Hizmetlerine Göre Sınıflandırılması”, Kent Akademisi, Cilt. 10, Sayı. 31: 323-337.

Genç, Tolga (2013), "G7 Ülkelerinden Seçilen Üyelerin Makro Ekonomik Kriterlere göre FLOWSORT ve ELECTRE TRI Yöntemi ile Sınıflandırılması", Çukurova Üniversitesi Sosyal Bilimler Enstitüsü Dergisi, Cilt. 22, Sayı. 2: 333-348

Gitman, Lawrence J. (1992), Basic Managerial Finance, New York: Harper Collins Publishers.

Günay, Fatih; Karadeniz, Erdinç; Dalak, Selda (2018), "Türkiye'de En Yüksek Net Satış Gelirine Sahip 20 Şirketin Finansal Performanslarının Gri İlişkisel Analiz Yöntemiyle İncelenmesi”, Ömer Halisdemir Üniversitesi Iktisadi ve İdari Bilimler Fakültesi Dergisi, Cilt. 11, Sayı. 2: 51-73.

Ishizaka, Alessio; Nemery, Philippe (2013), Multi-Criteria Decision Analysis : Methods and Software. New York: John Wiley \& Sons, Incorporated. 
Keskin, Yasemin (2002), İşletmelerde Finansal Başarısızlığın Tahmini, Çok Boyutlu Model Önerisi ve Uygulaması, Hacettepe Üniversitesi, Sosyal Bilimler Enstitüsü, İ̧̧letme Anabilim Dalı (Yayımlanmış Doktora Tezi), Ankara.

Kılıç, Süleyman Bilgin (2005), “Avrupa Birliğine Üye ve Aday Ülkelerin Bazı Temel Makro Ekonomik Kriterlere Göre Sınıflandırıması: Çok Kriterli Karar Alma Analizine Dayalı Bir Modelin Tahmini”, Çukurova Üniversitesi Sosyal Bilimler Enstitüsü Dergisi, Cilt. 14, Sayı. 2: 339-352

Kurtaran Çelik, Melike (2009), Finansal Başarısızlık Tahmin Modellerinin iMKB'deki Firmalar İçin Karşılaştırmalı Analizi, Karadeniz Teknik Üniversitesi, Sosyal Bilimler Enstitüsü, İşletme Anabilim Dalı (Yayımlanmış Doktora Tezi), Trabzon

Mousseau, Vincent; Slowinski, Roman (1998), "Inferring an ELECTRE TRI Model from Assignment Examples”, Journal of Global Optimization, Vol. 12, No. 2: 157-174.

Mousseau, Vincent; Slowinski, Roman; Zielniewicz, Piotr (2000),"A User-Oriented Implementation of The ELECTRE-TRI Method, Integrating Preference Elicitation Support", Computers and Operations Research, Vol. 27, No. 7-8: 757777.

Nemery, Philippe (2009), On the Use of Multicriteria Ranking Methods in Sorting Problems. Universite Libre de Bruxelles, PhD Thesis, Belgium.

Nemery, Philippe; Lamboray, Claude (2008), "FlowSort: A Flow-Based Sorting Method with Limiting or Central Profiles", Top, Vol. 16, No. 1: 90-113.

Ohlson, James A. (1980), "Financial Ratios and the Probabilistic Prediction of Bankruptcy", Journal of Accounting Research, Vol. 18, No. 1: 109-131

Ömürbek, Nuri., Eren, Hande (2016), “Promethee, Moraa, Copras Yöntemleri ile Oran Analizi Sonuçlarının Değerlendirilmesi: Bir Uygulama”, Mehmet Akif Ersoy Üniversitesi Sosyal Bilimler Enstitüsü Dergisi, 174-187.

Önder, Emrah; Önder, Güler (2015), Analitik Hiyerarşi Süreci (ss. 21-74), Operasyonel, Yönetsel ve Stratejik Problemlerin Çözümünde Çok Kriterli Karar Verme Yöntemleri, Editörler: B. F. Yıldırım; E. Önder, Bursa: Dora Basım-Yayın Dağıtım.

Saaty, Thomas L. (2007), "The Analytic Hierarchy and Analytic Network Measurement Processes: Applications to Decisions Under Risk", European Journal of Pure and Applied Mathematics, Vol. 1, No. 1: 122-196.

Saaty, Thomas L. (2008), "Decision Making with The Analytic Hierarchy Process", International Journal of Services Sciences, Vol. 1, No. 1: 83-98.

Sepulveda, Juan M. ve Derpich, Ivan S. (2017), "Automated Reasoning for Supplier Performance Appraisal in Supply Chains", Procedia Computer Science, C. 31, ss. 966-975.

Sarrazin, Renaud; De Smet, Yves ve Rosenfeld, Jean (2017), "An Extension of PROMETHEE to Interval Clustering", Omega, ss. 1-10.

Slowinski, Roman., ve Zopounidis, Constantin (1995), "Application of the Rough Set Approach to Evaluation of Bankruptcy Risk", Intelligent Systems in Accounting, Finance and Management, Vol. 4, No. 1: 27-41.

Torun, Talip (2007), Finansal Başarısızlık Tahmininde Geleneksel İstatistiki Yöntemlerle Yapay Sinir Ağlarının Karşılaştırılması ve Sanayi İşletmeleri Üzerinde Uygulama, Erciyes Üniversitesi, Sosyal Bilimler Entitüsü, İşletme Anabilim Dalı (Yayımlanmış Doktora Tezi), Erciyes.

Triantaphyllou, Evangelos; Mann, Stuart H. (1995), "Using The Analytic Hierarchy Process for Decision Making in Engineering Applications: Some Challenges", International Journal of Industrial Engineering: Applications and Practice, Vol. 2, No. 1: 35-44.

Vargas, Luis G. (1990), “An Overview of the Analytic Hierarchy Process and its Applications”, European Journal of Operational Research, Vol. 48, No. 1: 2-8.

Vatansever, Kemal; Aydın, Sinan (2014), “Finansal Başarısızlığın Öngörülmesinde Çok Kriterli Karar Verme Analizine Dayalı Bir Araştırma”, Dumlupınar Üniversitesi Sosyal Bilimler Dergisi, Sayı. 41: 163-176.

Yıldız, Birol (1999), Finansal Başarısızlığın Öngörülmesinde Yapay Sinir Ağı Kullanımı ve Ampirik Bir Çalışma, Dumlupınar Üniversitesi, Sosyal Bilimler Entitüsü, İşletme Anabilim Dalı (Yayımlanmamış Doktora Tezi), Kütahya.

Yükçü, Süleyman; Kaplanoğlu, Emre (2015), “Çok Kriterli Karar Verme Yöntemleriyle Gözaltı Pazarı Şirketlerinin Finansal Performanslarının Belirlenmesi”, Muhasebe Bilim Dünyası Dergisi, Cilt. 17, Sayı. 3: 587-616.

Zopounidis, Constantin, Paraschou, Dimitra, (1998), "Multicriteria Decision Aid Methods for the Prediction of Business Failure", Springer: https://www.springer.com/us/book/9780792349006, (Erişim: 25.12.2018). 
Eskişehir Osmangazi Üniversitesi iiBF Dergisi

Ek 1. Başlangıç Karar Matrisi

\begin{tabular}{|c|c|c|c|c|c|c|c|c|c|c|}
\hline & $\begin{array}{l}5 \\
\vdots \\
\vdots \\
0\end{array}$ & 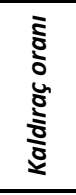 & $\begin{array}{l}\bar{\vdots} \\
\vdots \\
\vdots \\
z \\
z\end{array}$ & 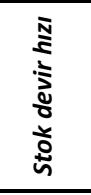 & 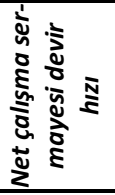 & 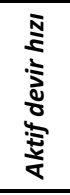 & 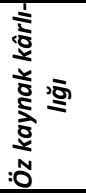 & 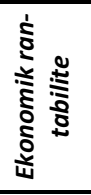 & 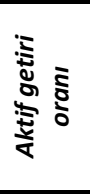 & 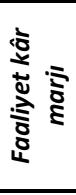 \\
\hline ALYAG & 0,43 & 0,47 & 0,7 & 26,58 & $-3,41$ & 0,92 & $-0,19$ & $-0,07$ & $-0,06$ & 0 \\
\hline AEFES & 1,78 & 0,41 & 0,13 & 5,42 & 5,13 & 0,5 & $-0,03$ & $-0,01$ & $-0,02$ & 0,09 \\
\hline AVOD & 1,2 & 0,54 & 0,4 & 3,78 & 11,55 & 0,93 & 0,02 & 0,02 & 0,01 & 0,1 \\
\hline BANVT & 0,86 & 0,75 & 0,91 & 8,43 & $-18,19$ & 1,96 & $-0,23$ & $-0,02$ & $-0,02$ & 0,02 \\
\hline CCOLA & 1,56 & 0,53 & 0,2 & 7,34 & 7,43 & 0,83 & 0,1 & 0,06 & 0,05 & 0,11 \\
\hline DARDL & 0,19 & 3,93 & 3,45 & 12,31 & $-1,35$ & 3,78 & 0,15 & $-0,43$ & $-0,43$ & 0,06 \\
\hline EKIZ & 0,74 & 0,86 & 0,44 & 24,48 & $-4,96$ & 0,56 & $-0,07$ & $-0,01$ & $-0,01$ & 0,01 \\
\hline ERSU & 3,46 & 0,26 & 0,12 & 1,87 & 1,93 & 0,56 & $-0,04$ & $-0,03$ & $-0,03$ & $-0,04$ \\
\hline FRIGO & 1,14 & 0,75 & 0,41 & 2,3 & 13,73 & 0,78 & $-0,14$ & $-0,04$ & $-0,04$ & $-0,01$ \\
\hline KRSAN & 1,27 & 0,58 & 0,49 & 0 & 0 & 0 & $-0,07$ & $-0,03$ & $-0,03$ & 0 \\
\hline KENT & 1,71 & 0,37 & 0,32 & 9,03 & 5,27 & 1,19 & 0,06 & 0,06 & 0,04 & 0,04 \\
\hline KERVT & 0,55 & 0,96 & 0,88 & 3,07 & $-1,47$ & 0,58 & $-3,59$ & $-0,15$ & $-0,13$ & 0,03 \\
\hline KNFRT & 6,25 & 0,17 & 0,13 & 1,25 & 1,66 & 1,16 & 0,21 & 0,23 & 0,18 & 0,2 \\
\hline KRSTL & 2,81 & 0,26 & 0,25 & 5,59 & 1,53 & 0,68 & 0,01 & 0,01 & 0 & 0 \\
\hline MERKO & 1,56 & 0,43 & 0,39 & 4,26 & 11,05 & 2,44 & 0,38 & 0,21 & 0,22 & 0,06 \\
\hline MRTGG & 1,67 & 1,21 & 0,47 & 0,22 & 0,07 & 0,02 & 1,17 & $-0,26$ & $-0,25$ & $-12,3$ \\
\hline OYLUM & 0,66 & 0,54 & 0,46 & 9,16 & $-4,13$ & 0,63 & $-0,06$ & $-0,05$ & $-0,03$ & $-0,05$ \\
\hline PENGD & 1,06 & 0,68 & 0,39 & 2,38 & 27,03 & 0,59 & $-0,21$ & $-0,06$ & $-0,07$ & $-0,1$ \\
\hline PETUN & 1,47 & 0,23 & 0,17 & 12,14 & 15,08 & 1,24 & 0,13 & 0,11 & 0,1 & 0,07 \\
\hline PINSU & 0,82 & 0,69 & 0,3 & 8,68 & $-14,18$ & 0,8 & $-0,34$ & $-0,14$ & $-0,1$ & $-0,12$ \\
\hline PNSUT & 1,42 & 0,32 & 0,25 & 8,17 & 11,36 & 1,21 & 0,16 & 0,11 & 0,11 & 0,06 \\
\hline SELGD & 1,67 & 0,5 & 0,47 & 5,43 & 2,09 & 0,65 & $-0,01$ & 0,01 & 0 & 0,02 \\
\hline TATGD & 1,98 & 0,47 & 0,38 & 3,78 & 3,29 & 1,23 & 0,43 & 0,05 & 0,23 & 0,06 \\
\hline TKURU & 2,6 & 0,56 & 0,2 & 1,29 & 1,12 & 0,37 & $-0,47$ & $-0,21$ & $-0,21$ & $-0,49$ \\
\hline TUKAS & 1,64 & 0,82 & 0,48 & 1,78 & 2,06 & 0,63 & $-1,01$ & $-0,18$ & $-0,33$ & $-0,07$ \\
\hline TBORG & 1,43 & 0,46 & 0,45 & 5,95 & 4,56 & 0,89 & 0,34 & 0,23 & 0,18 & 0,24 \\
\hline ULUUN & 1,38 & 0,67 & 0,65 & 6,18 & 7,64 & 1,87 & 0,09 & 0,04 & 0,03 & 0,04 \\
\hline ULKER & 3,1 & 0,61 & 0,21 & 11,12 & 2,1 & 0,91 & 0,19 & 0,08 & 0,07 & 0,1 \\
\hline VANGD & 7,01 & 0,05 & 0,12 & 5,43 & 0,44 & 0,12 & $-0,17$ & $-0,18$ & $-0,15$ & $-1,54$ \\
\hline KILER & 1,34 & 0,79 & 0,49 & 1,98 & 6,79 & 1,13 & $-0,15$ & $-0,03$ & $-0,03$ & 0,02 \\
\hline
\end{tabular}


Ek 2. Tanımlanan Fonksiyonlar Yardımıyla Elde Edilen Karar Matrisi

\begin{tabular}{|c|c|c|c|c|c|c|c|c|c|c|}
\hline & $\begin{array}{l}5 \\
\vdots \\
\vdots \\
\vdots \\
\vdots\end{array}$ & \begin{tabular}{l}
$\vdots$ \\
$\vdots$ \\
0 \\
$\vdots$ \\
$\frac{\vdots}{0}$ \\
\cline { 1 - 1 }
\end{tabular} & $\begin{array}{l}\bar{z} \\
\vdots \\
\vdots \\
\frac{y}{2}\end{array}$ & 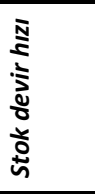 & 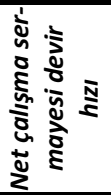 & 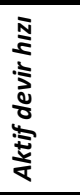 & 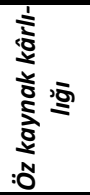 & 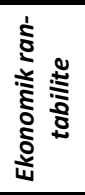 & 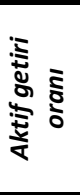 & 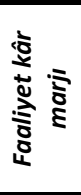 \\
\hline ALYAG & 0,22 & 1,00 & 0,85 & 26,58 & $-3,41$ & 0,92 & $-0,19$ & $-0,07$ & $-0,06$ & 0,00 \\
\hline AEFES & 0,89 & 1,00 & 1,00 & 5,42 & 5,13 & 0,50 & $-0,03$ & $-0,01$ & $-0,02$ & 0,09 \\
\hline AVOD & 0,60 & 1,00 & 0,96 & 3,78 & 11,55 & 0,93 & 0,02 & 0,02 & 0,01 & 0,1 \\
\hline BANVT & 0,43 & 0,94 & 0,78 & 8,43 & $-18,19$ & 1,96 & $-0,23$ & $-0,02$ & $-0,02$ & 0,02 \\
\hline CCOLA & 0,78 & 1,00 & 1,00 & 7,34 & 7,43 & 0,83 & 0,10 & 0,06 & 0,05 & 0,11 \\
\hline DARDL & 0,09 & 0,00 & 0,00 & 12,31 & $-1,35$ & 3,78 & 0,15 & $-0,43$ & $-0,43$ & 0,06 \\
\hline EKIZ & 0,37 & 0,89 & 0,95 & 24,48 & $-4,96$ & 0,56 & $-0,07$ & $-0,01$ & $-0,01$ & 0,01 \\
\hline ERSU & 0,71 & 1,00 & 1,00 & 1,87 & 1,93 & 0,56 & $-0,04$ & $-0,03$ & $-0,03$ & $-0,04$ \\
\hline FRIGO & 0,57 & 0,94 & 0,96 & 2,30 & 13,73 & 0,78 & $-0,14$ & $-0,04$ & $-0,04$ & $-0,01$ \\
\hline KRSAN & 0,64 & 1,00 & 0,93 & 0,00 & 0,00 & 0,00 & $-0,07$ & $-0,03$ & $-0,03$ & 0,00 \\
\hline KENT & 0,86 & 1,00 & 0,99 & 9,03 & 5,27 & 1,19 & 0,06 & 0,06 & 0,04 & 0,04 \\
\hline KERVT & 0,28 & 0,85 & 0,79 & 3,07 & $-1,47$ & 0,58 & $-3,59$ & $-0,15$ & $-0,13$ & 0,03 \\
\hline KNFRT & 0,15 & 1,00 & 1,00 & 1,25 & 1,66 & 1,16 & 0,21 & 0,23 & 0,18 & 0,2 \\
\hline KRSTL & 0,84 & 1,00 & 1,00 & 5,59 & 1,53 & 0,68 & 0,01 & 0,01 & 0,00 & 0,00 \\
\hline MERKO & 0,78 & 1,00 & 0,97 & 4,26 & 11,05 & 2,44 & 0,38 & 0,21 & 0,22 & 0,06 \\
\hline MRTGG & 0,83 & 0,75 & 0,94 & 0,22 & 0,07 & 0,02 & 1,17 & $-0,26$ & $-0,25$ & $-12,3$ \\
\hline OYLUM & 0,33 & 1,00 & 0,94 & 9,16 & $-4,13$ & 0,63 & $-0,06$ & $-0,05$ & $-0,03$ & $-0,05$ \\
\hline PENGD & 0,53 & 0,97 & 0,97 & 2,38 & 27,03 & 0,59 & $-0,21$ & $-0,06$ & $-0,07$ & $-0,1$ \\
\hline PETUN & 0,74 & 1,00 & 1,00 & 12,14 & 15,08 & 1,24 & 0,13 & 0,11 & 0,10 & 0,07 \\
\hline PINSU & 0,41 & 0,96 & 1,00 & 8,68 & $-14,18$ & 0,8 & $-0,33$ & $-0,14$ & $-0,1$ & $-0,12$ \\
\hline PNSUT & 0,71 & 1,00 & 1,00 & 8,17 & 11,36 & 1,21 & 0,16 & 0,11 & 0,11 & 0,06 \\
\hline SELGD & 0,83 & 1,00 & 0,94 & 5,43 & 2,09 & 0,65 & $-0,01$ & 0,01 & 0,00 & 0,02 \\
\hline TATGD & 0,99 & 1,00 & 0,97 & 3,78 & 3,29 & 1,23 & 0,43 & 0,05 & 0,23 & 0,06 \\
\hline TKURU & 0,88 & 1,00 & 1,00 & 1,29 & 1,12 & 0,37 & $-0,47$ & $-0,21$ & $-0,21$ & $-0,49$ \\
\hline TUKAS & 0,82 & 0,91 & 0,93 & 1,78 & 2,06 & 0,63 & $-1,01$ & $-0,18$ & $-0,33$ & $-0,07$ \\
\hline TBORG & 0,72 & 1,00 & 0,94 & 5,95 & 4,56 & 0,89 & 0,34 & 0,23 & 0,18 & 0,24 \\
\hline ULUUN & 0,69 & 0,97 & 0,87 & 6,18 & 7,64 & 1,87 & 0,09 & 0,04 & 0,03 & 0,04 \\
\hline ULKER & 0,78 & 0,99 & 1,00 & 11,12 & 2,10 & 0,91 & 0,19 & 0,08 & 0,07 & 0,10 \\
\hline VANGD & 0,00 & 1,00 & 1,00 & 5,43 & 0,44 & 0,12 & $-0,17$ & $-0,18$ & $-0,15$ & $-1,54$ \\
\hline KILLR & 0,67 & 0,92 & 0,93 & 1,98 & 6,79 & 1,13 & $-0,15$ & $-0,03$ & $-0,03$ & 0,02 \\
\hline
\end{tabular}


Eskişehir Osmangazi Üniversitesi iiBF Dergisi

Ek 3. Normalize Edilmiş Karar Matrisi

\begin{tabular}{|c|c|c|c|c|c|c|c|c|c|c|}
\hline & $\begin{array}{l}5 \\
\vdots \\
\vdots \\
0\end{array}$ & 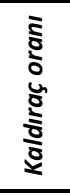 & $\begin{array}{l}\bar{\vdots} \\
\vdots \\
\vdots \\
\vdots \\
z\end{array}$ & 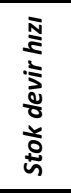 & 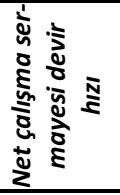 & 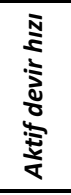 & $\begin{array}{l}\frac{1}{1} \\
\frac{1}{0} \\
\frac{1}{0} \\
\frac{0}{0} \\
\frac{0}{0} \\
: 0\end{array}$ & 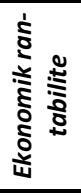 & 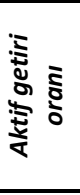 & 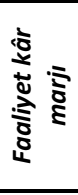 \\
\hline ALYAG & 0,22 & 1 & 0,85 & 1 & 0,33 & 0,24 & 0,71 & 0,55 & 0,56 & 0,98 \\
\hline AEFES & 0,9 & 1 & 1 & 0,2 & 0,52 & 0,13 & 0,75 & 0,64 & 0,62 & 0,99 \\
\hline AVOD & 0,6 & 1 & 0,96 & 0,14 & 0,66 & 0,25 & 0,76 & 0,68 & 0,67 & 0,99 \\
\hline BANVT & 0,4 & 0,94 & 0,78 & 0,32 & 0 & 0,52 & 0,71 & 0,62 & 0,62 & 0,98 \\
\hline CCOLA & 0,8 & 1 & 1 & 0,28 & 0,57 & 0,22 & 0,78 & 0,74 & 0,73 & 0,99 \\
\hline DARDL & 0,1 & 0 & 0 & 0,46 & 0,37 & 1 & 0,79 & 0 & 0 & 0,99 \\
\hline EKIZ & 0,4 & 0,89 & 0,95 & 0,92 & 0,29 & 0,15 & 0,74 & 0,64 & 0,64 & 0,98 \\
\hline ERSU & 0,7 & 1 & 1 & 0,07 & 0,44 & 0,15 & 0,75 & 0,61 & 0,61 & 0,98 \\
\hline FRIGO & 0,6 & 0,94 & 0,96 & 0,09 & 0,71 & 0,21 & 0,72 & 0,59 & 0,59 & 0,98 \\
\hline KRSAN & 0,7 & 1 & 0,93 & 0 & 0,4 & 0 & 0,74 & 0,61 & 0,61 & 0,98 \\
\hline KENT & 0,9 & 1 & 0,99 & 0,34 & 0,52 & 0,31 & 0,77 & 0,74 & 0,71 & 0,98 \\
\hline KERVT & 0,3 & 0,85 & 0,79 & 0,12 & 0,37 & 0,15 & 0 & 0,42 & 0,45 & 0,98 \\
\hline KNFRT & 0,2 & 1 & 1 & 0,05 & 0,44 & 0,31 & 0,8 & 1 & 0,92 & 1 \\
\hline KRSTL & 0,9 & 1 & 1 & 0,21 & 0,44 & 0,18 & 0,76 & 0,67 & 0,65 & 0,98 \\
\hline MERKO & 0,8 & 1 & 0,97 & 0,16 & 0,65 & 0,65 & 0,83 & 0,97 & 0,98 & 0,99 \\
\hline MRTGG & 0,8 & 0,75 & 0,94 & 0,01 & 0,4 & 0,01 & 1 & 0,26 & 0,27 & 0 \\
\hline OYLUM & 0,3 & 1 & 0,94 & 0,34 & 0,31 & 0,17 & 0,74 & 0,58 & 0,61 & 0,98 \\
\hline PENGD & 0,5 & 0,97 & 0,97 & 0,09 & 1 & 0,16 & 0,71 & 0,56 & 0,55 & 0,97 \\
\hline PETUN & 0,8 & 1 & 1 & 0,46 & 0,74 & 0,33 & 0,78 & 0,82 & 0,8 & 0,99 \\
\hline PINSU & 0,4 & 0,96 & 1 & 0,33 & 0,09 & 0,21 & 0,68 & 0,44 & 0,5 & 0,97 \\
\hline PNSUT & 0,7 & 1 & 1 & 0,31 & 0,65 & 0,32 & 0,79 & 0,82 & 0,82 & 0,99 \\
\hline SELGD & 0,8 & 1 & 0,94 & 0,2 & 0,45 & 0,17 & 0,75 & 0,67 & 0,65 & 0,98 \\
\hline TATGD & 1 & 1 & 0,97 & 0,14 & 0,48 & 0,33 & 0,84 & 0,73 & 1 & 0,99 \\
\hline TKURU & 0,9 & 1 & 1 & 0,05 & 0,43 & 0,1 & 0,66 & 0,33 & 0,33 & 0,94 \\
\hline TUKAS & 0,8 & 0,91 & 0,93 & 0,07 & 0,45 & 0,17 & 0,54 & 0,38 & 0,15 & 0,98 \\
\hline TBORG & 0,7 & 1 & 0,94 & 0,22 & 0,5 & 0,24 & 0,83 & 1 & 0,92 & 1 \\
\hline ULUUN & 0,7 & 0,97 & 0,87 & 0,23 & 0,57 & 0,49 & 0,77 & 0,71 & 0,7 & 0,98 \\
\hline ULKER & 0,8 & 0,99 & 1 & 0,42 & 0,45 & 0,24 & 0,79 & 0,77 & 0,76 & 0,99 \\
\hline VANGD & 0 & 1 & 1 & 0,2 & 0,41 & 0,03 & 0,72 & 0,38 & 0,42 & 0,86 \\
\hline KILER & 0,7 & 0,92 & 0,93 & 0,07 & 0,55 & 0,3 & 0,72 & 0,61 & 0,61 & 0,98 \\
\hline
\end{tabular}




\section{Extended Summary}

\section{Estimation of Financial Failure of Enterprises with AHP Based ELECTRE TRI and FLOWSORT Methods}

The aim of this article is to classify enterprises as financially successful or unsuccessful by using Multi Criteria Decision Making Methods (MCDM) with ELECTRE TRI and FLOWSORT methods and to measure the classification power of these methods.

In the application process, first of all 30 enterprises are classified as successful / unsuccessful within the framework of 3 different failure criteria which are accepted in finance and a prediction set is formed. This prediction set was accepted as the correct classification, and MCDM were used to estimate this classification.

In the process of applying the methods, 10 financial ratios (operating profit margin, return on equity, return on asset ratio, economic rantability, working capital turnover, stock turnover, working capital ratio, asset turnover, financial leverage ratio, short term liabilities) were determined as criteria by using expert opinion. Analytical Hierarchy Process (AHP) method, which is a subjective weighting method that can measure the criteria by pairwise comparison, was used in the calculation of the significance levels between these criteria. For the classification, ELECTRE TRI and FLOWSORT methods were used. ELECTRE TRI is a multi-criteria classification method that allows assigning alternatives to predefined classes. The FLOWSORT method is based on the PROMETHEE methodology, similar to the ELECTRE TRI method, which allows assigning alternatives to predefined classes via central or limiting sections.

To be able to apply aforementioned methods, the directions of the criteria should be known. However, some of the criteria used in the study are non-directional. Therefore, in the article, new functions in which criterion directions can be determined are defined and the implementation is made in food, drink and tobacco sectors.

The study is thought to be original in two respects. Firstly, in the literature review, no previous study could be found on the prediction of financial failure using FLOWSORT method. Second, definition of the functions for determining the correct direction of the criteria used. In order to implement the MCDM correctly, the criterion direction must be correctly determined as benefit (maximization) or cost (minimization) and the application should be made accordingly. However, in the literature studies, for example, the criterion direction of the current ratio was taken as maximization. However, the current rate of ideal values in Turkey is 2 . This ratio is not desired neither below nor above 2 value. So the current ratio is actually a non-directional criterion. Or it is sufficient if the leverage ratio is below 0,6 in Turkey. Therefore, in this study, for the first-time new functions have been defined for the ratios to be used for determining the criteria directions correctly.

The main limitation of the study comes from subjective approaches. The first limitation is the subjectivity in forming the prediction set. Because it is thought that if different criteria are used instead of 3 criteria used in the formation of the forecast set, the forecast values would change. Similarly, the criteria and the weight values of these criteria were determined by the experts with a subjective approach. It is possible to obtain different criteria and weight values with different experts. The final limitation of the study is the subjective approach in determining the limiting sectional values of the classes in FLOWSORT method.

According to expert opinion, highest weight criterion is operating profit margin with $25 \%$. Weight of the other criterions are follows: return on equity (17\%), return on asset ratio ( $13 \%)$, economic rantability (12\%), working capital turnover $(8 \%)$, stock turnover (7\%), working capital ratio (6\%), asset turnover (5\%), financial leverage ratio $(4 \%)$ and short term liabilities (3\%)

As regards to the results of ELECTRE TRI method, 7 out of 30 enterprises were misclassified. The correct classification rate of the method is $77 \%$ and the wrong classification rate is $23 \%$. One successful enterprise is classified as unsuccessful. The correct classification rate of successful enterprises is $93 \%$ and the wrong classification rate is $7 \%$. Among the unsuccessful enterprises, 6 were classified as successful. The correct classification rate of failed enterprises was $60 \%$ and the wrong classification rate was $40 \%$.

In the FLOWSORT method, 13 enterprises out of 30 were classified as wrong. The correct classification rate of the method is $57 \%$ and the wrong classification rate is $43 \%$. The method correctly classified all successful businesses. The correct classification rate of successful enterprises is $100 \% .13$ of the unsuccessful enterprises were classified as successful. The correct classification rate of failed enterprises is $13 \%$ and the wrong classification rate is $87 \%$.

It is thought that the financial ratios used in the MCDM studies in the field of finance are neglected in terms of ignoring the values below or above a certain level and calling these values directly increasing or decreasing. The functions described in this study, it is believed that it can give an idea to the new MCDM studies in the field of finance and contribute to the literature with this new perspective. 


\section{Eskişehir Osmangazi Üniversitesi IïB Dergisi}

Besides the application of other multi-criteria classification and statistical methods such as UTADIS, AHPSORT, making better function definitions or quantitative criteria it is thought that better solutions can be proposed in the future with applications that take into account qualitative criteria such as the business experience of the managers, the market area of the business and the competitiveness. 